Chapter 13

\title{
Biomaterials and Stem Cell Therapies for Injuries Associated to Skeletal Muscular Tissues
}

Tiago Pereira, Andrea Gärtner, Irina Amorim, Paulo Armada-da-Silva, Raquel Gomes,

Cátia Pereira, Miguel L. França, Diana M. Morais,

Miguel A. Rodrigues, Maria A. Lopes, José D. Santos,

Ana Lúcia Luís and Ana Colette Maurício

Additional information is available at the end of the chapter

http://dx.doi.org/10.5772/ 53335

\section{Introduction}

Skeletal muscle injuries are common in humans, particularly in athletes and it is important to develop new methods to improve muscle regeneration. Skeletal muscle has good regenerative ability, but the extent of muscle injury might prevent complete regeneration, especially in terms of functional recovery. Severe lesions, like those originated by trauma associated with loss of healthy muscular tissue and development of fibrous tissue scar and irreversible muscular atrophy after long-term peripheral nervous injuries are examples of those situations where regeneration is limited. An alternative approach for the restoration of the damaged skeletal muscular tissue, considered to be an ultimate treatment of some traumatic or degenerative diseases, is the transplantation of stem cells that limit the fibrosis and the atrophy of the involved muscle masses, and even imply the myocytes regeneration and local revascularization [1]. Stem cells and regenerative medicine is a fast emerging field with rapid strides of progress and focus on human health. Successful clinical use of stem cells in regenerative medicine depends on 3 important features:

i. stem cells can grow and divide indefinitely,

ii. stem cells can differentiate into specialized cell types, like skeletal muscle; and

iii. the stem cells can be delivered to the site of lesion associated to biomaterials, nowadays available with excellent characteristics concerning biocompatibility. 
The purpose of this review is to describe the current research lines in the skeletal muscle regeneration field, with special emphasis to the work performed by our research group in testing different biomaterials and cellular therapies, emphasizing the use of mesenchymal stem cells (MSCs) isolated from the Wharton's jelly of the umbilical cord. We also focused our research in developing skeletal muscular lesion models which could be reproducible. It is important to state, that a multidisciplinary team has a crucial role in the development of these biomaterials associated to cellular systems, and in pre-clinical tests. MSCs comprise a rare population of multipotent progenitor cells with a great therapeutic potential since they are capable of self-renewal and multi-lineage differentiation. Due to this ability, MSCs appear to be an attractive tool in the context of Tissue Engineering and cell-based therapy concerning skeletal muscle regeneration. Several biomaterials associated to MSCs from the Wharton's jelly of the umbilical cord have been tested in standard lesions of the rat muscle and the results of these tests will be discussed here. The umbilical cord matrix is an important and safe source of MSCs with positive effects in nerve and skeletal muscle regeneration, with no ethical or technical issues.

\section{Skeletal muscle tissue}

\subsection{Basic structure and terminology}

The muscle fibers are the basic contractile units of skeletal muscles. They are individually surrounded by a connective tissue layer and grouped into bundles to form a skeletal muscle [1]. Each muscle is surrounded by a layer of dense connective tissue - the epimysium which is continuous with the tendon. The muscle is composed of numerous bundles of muscle fibers - fascicles - which are separated from each other by another connective tissue layer named perimysium. The endomysium is the connective tissue that separates individual muscle fibers from each other. Mature muscle cells are termed muscle fibers or myofibers. Each myofiber is a multinucleate syncytium formed by fusion of immature muscle cells termed myoblasts. In the cytoplasm of each myofiber - the sarcoplasm - lays the contractile apparatus of the cell which is composed of sarcomeres arranged in series to form myofibrils, which give myofibers their striated appearance. The sarcomeres contain a number of proteins, including alpha-actinin - which is the major constituent of the $\mathrm{Z}$ band - and actin and myosin, which are the major components of the thin and thick filaments, respectively. The sarcoplasm, located between the myofibrils, is called the intermyofibrillar network and contains the mitochondria, lipid, glycogen, T-tubules, and sarcoplasmic reticulum [1-3]. Skeletal muscles are highly vascularized to provide essential nutrients for muscle function. As the myofiber matures, it is contacted by a single motoneuron and expresses characteristic molecules for contractile function, principally different myosin heavy chain isoforms and metabolic enzymes. Both the motoneuron and the myoblast origin have been implicated to play a role in specifying the myofiber contractile properties, although the precise mechanisms remain to be defined [1]. 


\subsubsection{Fiber type}

Individual adult skeletal muscles are composed of a mixture of myofibers with different physiological properties, ranging from a slow-contracting/fatigue-resistant type to a fastcontracting/non-fatigue-resistant type. The proportion of each fiber type within a muscle determines its overall contractile properties [1]. The slow contracting soleus muscle is rich in myofibers expressing the slow type I myosin heavy chain isoform, whereas the fast contracting plantaris muscle is devoid of slow type I myofibers [1-3]. The most informative methods to delineate muscle fiber types are based on specific myosin profiles, specially the myosin heavy chain (MHC) isoform complement. According to the major MHC isoforms found in adult mammalian skeletal muscles, the following pure fiber types exist: slow type I with $\mathrm{MHCIb}$, and three fast types, namely type IIA with MHCIIa, type IID with MHCIId and type IIB with MHCIIb [4]. Despite having different physiological properties, the basic mechanism of muscle contraction is similar in all myofiber types and is the result of a "sliding mechanism" of the myosin-rich thick filament over the actin-rich thin filament after neuronal activation [5]. The connective tissue framework in skeletal muscle combines the contractile myofibers into a functional unit, in which the contraction of myofibers is transformed into movement via myotendinous junctions at their ends, where myofibers attach to the skeleton by tendons. Thus the functional properties of skeletal muscle depend on the maintenance of a complex framework of myofibers, motor neurons, blood vessels, and extracellular connective tissue matrix [1].

\subsection{Regeneration of the skeletal muscle}

Regeneration is a unique adaptation of skeletal muscle that occurs in response to injury. Following direct trauma or disease, the regeneration of skeletal muscle results in restoration, to some degree, of the original structure and function of the muscle tissue [6]. Skeletal muscle regeneration is a physiological response of the tissue to traumatic or pathological injuries and its progress depends on the type of damaged muscle and the extent of the injury. Under normal conditions, the regenerated muscle is morphologically and functionally indistinguishable from undamaged muscle [1]. Regeneration resembles the process of formation of skeletal muscle during embryogenesis. Skeletal myogenesis begins in the somites where multipotencial mesodermal cells commit to the myogenic lineage. These mononucleated myoblasts then fuse and form multinucleated cells (myotubes) that ultimately develop into mature myofibers [1,7]. During the course of muscle development, a distinct subpopulation of myoblasts fails to differentiate and remains associated with the surface of the developing myofiber as quiescent muscle satellite cells (SCs) in fully developed mature skeletal tissue [1, 7].

\subsubsection{Satellite Cells and other cells involved in regeneration of skeletal muscle tissue}

During regeneration and muscle repair, SCs fuse together or to the existing fibers to form new muscle fibers [8]. Although the number of SCs is greatly reduced in aged muscle, those remaining maintain an intrinsic capacity to regenerate the muscle tissue as efficiently as in younger muscles. A vital condition for successful regeneration is the presence of SCs in the uninjured portions of the basal membrane of the myofiber, along with its ability for reinner- 
vation and revascularization. After a skeletal muscle injury, myofibers become completely desintegrated via myolysis and the SCs are realeased from the basal membrane. From this point SCs start to divide and are capable of differentiating into muscle fibers, reestablishing myofiber's architecture and restoring the muscle function $[9,10]$. In post-natal skeletal muscle, PW1 expression is detected in SCs and a subset of interstitial cells and is markedly upregulated during muscle regeneration [11]. These interstitial multipotent stem cells are extralaminal and exhibit fibroblastic morphology but do not express the same myogenic markers such as Pax7 [10]. PW1 ${ }^{+} /$Pax7 $^{-}$interstitial cells (PICs) are myogenic in vitro and efficiently contribute to skeletal muscle regeneration in vivo as well as generating satellite cells and PICs. PICs show bipotential behavior in vitro, generating both smooth and skeletal muscle. Isolated PICs do not express Pax7 or MyoD, but they convert to a Pax7 $/ \mathrm{MyoD}^{+}$state before forming skeletal muscle in vitro. PICs are not derived from a Pax3-expressing parental cell and thus do not share a satellite cell lineage; however, PICs do express Pax3 upon conversion to skeletal muscle. PICs are a key cell population that cannot be recruited into the skeletal muscle lineage in the absence of Pax7 function and is likely to contribute to the Pax7 muscle phenotype during postnatal growth. PICs are as abundant as SCs in muscle tissue and correspond to the only population of PW1+/Pax7- cells in vivo, requiring Pax7 for their myogenic capacity [11]. PDGFR $\alpha+$ mesenchymal progenitor cells located in the muscle interstitium were also identified as being distinct from SCs. Of the muscle-derived cell populations, only PDGFR $\alpha+$ cells show efficient adipogenic differentiation both in vitro and in vivo, being strongly inhibited by the presence of satellite cell-derived myofibres. These results suggest that PDGFR $\alpha+$ mesenchymal progenitors are the major contributor to ectopic fat cell formation in skeletal muscle that is more conspicuous in perimysium and particularly in perivascular space. The balance between satellite cell-dependent myogenesis and PDGFR $\alpha+$ cell-dependent adipogenesis, rather than multipotency of satellite cells, has a considerable impact on muscle homeostasis [12]. Hematopoietic and dendritic cells are also present in the perimysium of the skeletal tissue, as well as some lymphocytes and macrophages [10].

\subsubsection{Myogenic differentiation}

Cells derived from Pax3-expressing cells are myofibres and SCs [11]. Once activated, SCs express factors involved in the specification of the myogenic program, such as Pax-7, desmin, MNF $\alpha$, Myf5, MRF4 and MyoD. Activated SCs enter the cell cycle and proliferate as indicated by the expression of factors involved in cell cycle progression, such as PCNA and by the incorporation of BrDU. Recently, miRNAs have also been reported to regulate gene expression in skeletal muscle. Upon activation, SCs generate fusion-competent myoblasts and can self-renew at least to a limited extent. Any interruption in the proliferation or fusion of myoblasts, or any alterations in the extracellular matrix leads to the development of fibrosis, compromising the establishment of the correct muscular function $[8,10]$. Proliferative MyoD and/or Myf5 positive myogenic cells are termed myoblasts. Both SCs and myoblasts increase their cytoplasmic-nuclear ratio and can migrate along myofibers. Proliferating myoblasts withdraw from the cell cycle to become terminally differentiated myocytes that express the "late" myogenic regulatory factors (MRFs), Myogenin and MRF4, and subsequently musclespecific genes such as $\mathrm{MHC}$ and muscle creatine kinase $\left(\mathrm{CK}_{\mathrm{M}}\right)$, and stopping Pax7 expres- 
sion. Myogenic subpopulations have also been identified by their enriched M-cadherin and CD34 expression. M-cadherin can be considered to be a reliable marker for both quiescent and activated SCs. Once fusion of myogenic cells is completed, newly formed myofibers increase in size and myonuclei move to the periphery of the muscle fiber $[1,10,13]$.

\subsubsection{Degeneration}

This scenario changes dramatically when the muscle is damaged, in which muscle degeneration after acute injury is characterized by myofiber necrosis and is followed by inflammation, tissue reconstruction and remodeling [10]. The necrosis is triggered by disruption of the myofiber sarcolemma resulting in increased myofiber permeability. The disruption of myofiber integrity is reflected by increased serum levels of muscle proteins, such as CK (usually restricted to the myofiber cytosol) [1]. It has been hypothesized that increased $\mathrm{Ca}^{2+}$ influx after sarcolemmal or sarcoplasmic reticulum damage results in a loss of $\mathrm{Ca}^{2+}$ homeostasis and increased $\mathrm{Ca}^{2+}$-dependent proteolysis that drives tissue degeneration resulting in focal or total autolysis depending on the extent of the injury [1].

\subsubsection{Inflammation}

The early regenerative response in skeletal muscle is similar to that in other tissues and requires the coordinated regulation of inflammation, extracellular matrix remodeling, and myofiber growth [14]. The early phase of muscle injury is usually accompanied by the activation of mononucleated cells, mainly inflammatory cells and myogenic cells. Factors released by the injured muscle activate inflammatory cells residing within the muscle, which in turn provide the chemotactic signals to circulating immune cells. Neutrophils are the first immune cells to invade the injured muscle, with a significant increase in their number being observed as early as 1-6h after myotoxin or exercise-induced muscle damage. After neutrophil infiltration and $48 \mathrm{~h}$ post-injury, macrophages become the predominant inflammatory cell type within the site of injury. Macrophages infiltrate the injured site and through phagocytosis remove cellular debris and may affect other aspects of muscle regeneration by activating myogenic cells [1]. Testosterone has a documented ability to modulate the activity of immune, fibroblast, and myogenic precursor cells, which are all components of regeneration [14].

\section{Skeletal muscle injury models}

In order to study the process of muscle regeneration in a controlled and reproducible way, it was necessary to develop experimental models of muscle injury [1]. In this sense, a variety of experimental models that compromise skeletal muscle function or destroy this tissue is available. Each of the injury models can potentially have a different effect on the fate of resident cells and circulating cells within the muscle bed after the trauma [10]. A large number of studies, involving a variety of experimental injuries, such as injection of myotoxic agents, crush, ischemia, denervation and muscular dystrophies, demonstrate the unique ability of skeletal muscle for regeneration, irrespectively the precise method used to induce the initial 
injury [15]. In this review we will focus on chemical and mechanical models of skeletal muscle injury, adding a new model of muscle injury based on surgical myectomy, developed in order to mimic severe losses of skeletal muscle mass. Other models, like exercise and denervation, will also be outlined. The latter is not a model of injury but else of skeletal muscle disuse but that also can be used to investigate skeletal muscle remodeling. There is a variety of other genetic models that are essential in studying diseases like Duchenne muscle dystrophy ( $\mathrm{Mdx}$ mouse is currently the most widely used in this case) but will not be discussed in this review.

\subsection{Chemical methods of skeletal muscle injury}

The use of myotoxins, such as bupivacaine (Marcaine), cardiotoxin (CTX), and notexin (NTX) is perhaps the easiest and most reproducible way to induce muscle injury and regeneration. Myotoxins are also widely used to induce skeletal muscle injury because their inoculation by intramuscular injection does not require complex surgery. Several chemical agents are known to produce skeletal muscle damage. Severe muscle fiber damage, like breakdown of sarcolemma and myofibrils, has been described after intramuscular injections of $0.75 \%$ bupivacaine, $2 \%$ mepivacaine, or $2 \%$ lidocaine associated to epinephrine [18]. While lidocaine can cause rapid destruction of skeletal muscle fibers, long-acting anesthetics, like bupivacaine, are more often used to cause skeletal muscle injury in rodents [19].

\subsubsection{Bupivacaine}

The bupivacaine injection procedure is simple and quick, does not involve extensive surgery, and induces a regeneration process which is qualitatively similar to that observed in other model systems. Doses of 1.5 and 1\% wt/vol produce significant levels of muscle injury and subsequent regeneration, but these doses also produce large regions of ischemic muscle tissue. Doses of 0.75 and $0.5 \%$ bupivacaine are also effective in inducing regeneration and produce little or no ischemia [16]. Muscle fiber necrosis is extremely rapid after induced bupivacaine injury [14]. Injection of the drug into small skeletal muscles of rat or mouse leads to immediate and massive myonecrosis followed by phagocytosis of necrotic debris and a rapid and apparently complete regeneration of muscle fibers 3-4 wk after injection. The peak isometric twitch and tetanic tensions produced by rat fast-twitch extensor digitorum longus muscle injected with bupivacaine returns to normal values by $21 \mathrm{~d}$ after injection [17]. Morphological analysis has shown that many indexes of successful regeneration in healthy muscle can be completed within 2-3 weeks of recovery from injury [14]. The sequence of fiber breakdown induced by bupivacaine is similar to that of progressive muscular dystrophy [18] and it is also striking that the same types of muscle fibers are spared by both Duchenne's muscular dystrophy and bupivacaine toxicity. It has been suggested that bupivacaine may disrupt $\mathrm{Ca}^{2+}$ homeostasis in vivo, triggering $\mathrm{Ca}^{2+}$-activated cellular death pathways that include proteolysis. This suggestion is supported by the findings that

i. bupivacaine affects sarcoplasmic reticulum function in vitro, 
ii. extracellular $\mathrm{Ca}^{2+}$ omission delays the morphological changes and decreases the protein degradation rate that are observed in isolated rat soleus muscle exposed to bupivacaine, and

iii. bupivacaine uncouples isolated rat liver and heart mitochondria and decreases mitochondrial membrane potential and oxygen consumption both in cultured fibroblasts and Ehrlich tumor cells [19].

Extracellular $\mathrm{Ca}^{2+}$ plays a part in mediating the muscle damage caused by bupivacaine but other factors must also be involved [20]. For example macrophage invasion is necessary for complete degeneration of myofibrillar components [21]. Saito and Nonaka [22] injected $0,5 \mathrm{ml}$ of $0,5 \%$ bupivacaine after soleus muscle exposure of Wistar rats, and observed that SCs proliferation began at almost the same time as following muscle crush injuries. Bupivacaine is still commonly used for the purpose of studying the mechanisms of skeletal muscle regeneration following injury $[7,14,15,22]$.

\subsubsection{Cardiotoxin and Notexin}

Snake venom is known for a long time to directly affect the skeletal muscle, producing fibrillation, contractures and depolarization of the sarcolemma. Although initially ascribed to the phospholipase A content of this venom, muscle contracture and depolarization seem to be related to the cardiotoxic action of cobra venom [23]. Notexin (NTX) is a phospholipase A2 neurotoxin peptide extracted from snake venoms that blocks neuromuscular transmission by inhibition of acetylcholine release. Cardiotoxin (CTX) is also a peptide isolated from snake venoms, but it is a protein kinase C-specific inhibitor that appears to induce the depolarization and contraction of muscle cells, disruption of membrane structure, and lysis of various cell types [1]. CTX is postulated to be neurotoxic as its injection destroys neuromuscular junctions [24]. However, CTX might cause direct destruction of muscle tissues [25]. Snake CTX polypeptide is now known to be a potent inducer of muscle contracture with phospholipase A likely acting in accelerating the action of CTX rather than in augmenting it $[23,26]$. Dantrolene antagonizes CTX-induced contractures, suggesting a role for $\mathrm{Ca}^{2+} \mathrm{de}^{-}$ rived from the sarcoplasmic reticulum in CTX action. CTX rapidly lowers the threshold for $\mathrm{Ca}^{2+}$-induced $\mathrm{Ca}^{2+}$ release in heavy sarcoplasmic reticulum fractions. The mechanism of action involved in contractures of skeletal muscle appears to be related to the immediate and specific effect of CTX ( $\mathrm{Ca}^{2+}$ release by the sarcoplasmic reticulum) $[27,28]$.

A more recent study by Gutiérrez and Ownby [25] focused on the role of PLA $\mathrm{A}_{2}$ as important myotoxic components in these venoms suggesting that myotoxic $\mathrm{PLA}_{2} \mathrm{~s}$ binds to acceptors in the plasma membrane leading to its disruption and pronounced $\mathrm{Ca}^{2+}$ influx which, in turn, initiates a complex series of degenerative events associated with contracture, activation of calpains and cytosolic $\mathrm{Ca}^{2+}$-dependent $\mathrm{PLA}_{2} \mathrm{~S}$, and mitochondrial $\mathrm{Ca}^{2+}$ overload. Fourie et al. [30] already had suggested that the biological effects of CTX could be a consequence of inhibition of plasma membrane $\left(\mathrm{Ca}^{2+}+\mathrm{Mg}^{2+}\right)$-ATPases. The local myonecrosis is often associated with other effects, such as hemorrhage, blistering and edema, in a complex pattern of local tissue damage. Apart from membrane-active CTXs, snake venom hemorrhagic metallo- 
proteinases also cause myonecrosis, but the mechanism involved is likely to be an indirect one, probably related to ischemia [25]. CTX is a useful model for muscle regeneration that does not influence muscle architecture like basal lamina or microvasculature, making the regeneration process less complicated than other models like crush, where for example, inadequate blood supply might result in an increase of fibrosis. CTX injection also results in faster and more extensive muscle degeneration, and an earlier start of the reconstruction phase, than muscle crushing [24].

\subsection{Mechanical methods of skeletal muscle injury}

Crush injuries of the skeletal muscle can occur in considerable numbers following natural disasters or acts of war and terrorism. They can also occur sporadically after industrial accidents or following periods of unconsciousness from drug intoxication, anesthesia, trauma or cerebral events [31]. Crushing as a method of inducing muscle injury and regeneration was first described by Bassaglia and Gautron [32], and has since been used in several published research studies [24]. Muscle damage occurs at three distinct stages: at the time of the initial mechanical crushing force, during the period of ischemia and during the period of reperfusion [31]. It has been hypothesized that ischemia is the primary instigator of local muscle damage following crush injuries [33]. However, studies have shown that although skeletal muscle tissue can survive circulatory ischemia for $4 \mathrm{~h}$, the mechanical force sustained in crushing, along with ischemia, causes skeletal muscle death in only $1 \mathrm{~h}$. Studies of enzyme release suggest that most damage to myocytes occurs during the reperfusion stage rather than the ischemic stage [31]. Animal models of muscle injury should closely mimic the clinical situation. Among these models open crush lesion have been used frequently, allowing standardized evaluation of regeneration in a selected muscle. For application of the trauma, either forceps or custom-made devices have been used. There are two types of muscle-crush models described in the literature: the segmental crush and the complete crush, where only $4-6 \%$ of the fibers remain intact [34]. There are different forms to accomplish the segmental crush model but most of them include the use of a surgical instrument (hemostatic clamp e.g.) to produce a standardized closing force in a specific area of a muscle causing a compression contusion injury [35]. One of the important steps of this procedure is denervation, which makes the initial steps of regeneration less painful for the animal. Skeletal muscle contusion can also be performed without skin incision by dropping a mass over a selected muscle. This technique was used by Iwata, Fuchioka [36] employing a $640 \mathrm{~g}$ mass dropped from a $25 \mathrm{~cm}$ height onto an impactor (diameter $10 \mathrm{~mm}$ ) placed on the belly of the rat medial gastrocnemius. This procedure damaged around $47 \%$ of the entire cross-sectional area of both medial and lateral gastrocnemius. At day 2 postinjury, an intense inflammatory response and necrotized myofibers with infiltrated mononuclear cells were observed. No myotubes were found at this stage. However, a number of regenerative myotubes were detected at days 7,14 , and 21 days post-injury. This study also showed that normal locomotion recovers prior to isometric force and complete regeneration of the injured muscle [36]. The main disadvantage of the complete muscle crush is the potential damaging of myoneural junctions which triggers not only regeneration of muscle substance but also initial innervation deficits. These deficits always lead to impaired 
healing [34]. Histological analysis of muscle regeneration after crush injury shows an initial phase of inflammation followed by SCs activation, myotube regeneration and fibrosis of the muscle. It has been shown that development of fibrotic tissue is one of the main factors affecting the recovery of muscle function after traumatic muscle injury [34]. In a qualitative assessment performed by our group we tested the open crush lesion in the tibialis anterior (TA) muscle of adult Sasco Sprague rats. Different standardized force intensities, durations of muscle compression (30 seconds and 1 minute) and time points (3, 8, 15 and 21 days post-surgery) were considered for the histological evaluation of skeletal muscle injury. Hematoxilin-eosin (HE) and Masson's trichrome staining were employed in this preliminary study. At day 3 post-surgery, myofiber damage was evident and the lymph nodes were reactive due to the active inflammatory process. The presence of fibrosis was evident only following 15 days from the initial injury. This evaluation revealed that the crush model was not the most appropriate for in vivo evaluation of cellular therapies for skeletal muscle regeneration aid, since the extent of this injury type did not present the magnitude required to accurately appreciate the biological effects of MSCs utilization [38].

\subsection{Myectomy and myotomy}

The loss of a portion of a skeletal muscle poses a unique challenge for regeneration of muscle tissue and restoration of its normal structure and function [39]. In the event of large-scale soft tissue traumas, extensive loss of full-thickness native tissue architecture renders the wound site unable to support normal regeneration process. In severe tissue injuries the acute inflammatory response is followed by formation of a provisional fibrin matrix derived from trauma-associated blood clotting and this matrix is then infiltrated by type I collagenproducing fibroblasts [40]. In order to mimic those situations, new experimental models have been developed in which a defined portion of the muscle tissue is removed, creating a myectomy defect within the muscle. For example, Merrit et al. [39] removed a $0.5 \times 1.0 \mathrm{~cm}$ or a $1.0 \times 1.0 \mathrm{~cm}$ fraction of the gastrocnemius muscle of rats, creating a small and large defect respectively. This was accomplished lacerating the lateral side of the muscle with a \#9 scalpel blade. We have recently developed a novel experimental muscle injury model in the TA muscle of adult Sasco Sprague rat, by using a biopsy punch to create a standardized myectomy defect. Sasco Sprague male rats with 250-300g were used and after a standardized $5 \mathrm{~mm}$ diameter myectomy lesion in the mid-belly of the tibialis anterior muscle, the defect was completely filled with different vehicles and/or biomaterials, cellular suspensions containing $1 \times 10^{6}$ human MSCs isolated from Wharton's jelly and conditioned media (Figure 1). This concentrated media contains trophic factors secreted by MSCs during cell culture. In our research work, the myectomy model proved to be the most appropriate for a comprehensive and standard evaluation of the rat skeletal muscular regeneration ability. The regeneration process in other models of lesion, like simple muscle crush, did not present the magnitude required to accurately appreciate the biological effects of MSCs [38]. 


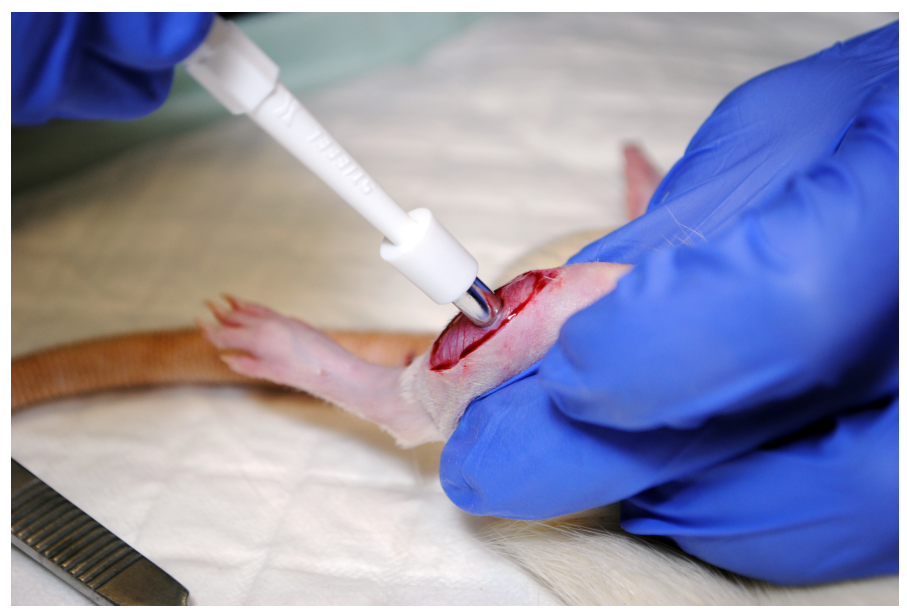

Figure 1. Biopsy punch for myectomy lesion creating a $5 \mathrm{~mm} \varnothing$ defect in the rat tibialis anterior (TA) muscle.

Another less invasive model of muscle injury has been used in a number of studies by producing a laceration injury (myotomy) [42-44]. In some cases this was obtained by a partial thickness (50\%) cut of gastrocnemius muscles in mice at $60 \%$ of their length from their distal insertion, through $75 \%$ of their width and then sutured with a modified Kessler stitch and simple sutures using a PDS 7.0 wire (Ethicon, Somerville, New Jersey) [43]. Other studies used a full-thickness $(100 \%)$ cut though $50 \%$ of the gastrocnemius muscle width [44]. The advantages of this model are its reproducibility and the ability to apply consistently precise injections into the laceration site [43].

\subsection{Denervation (indirect model)}

Innervation regulates skeletal muscle mass and muscle phenotype and peripheral nerve injury in the rat is a widely used model to investigate nerve regeneration and can also be employed as a model of muscle inactivity and muscle atrophy. Changes in the muscles may contribute to functional deficit after nerve injury [47]. Denervation induces muscle atrophy and 25 months post denervation muscle fibers cross sectional area of the extensor digitorium longus (EDL) muscle diminish to only $2.5 \%$ of control animals although their fascicular organization is maintained [47]. The effect of denervation on muscle atrophy is both activitydependent and activity-independent since the degree of hindlimb muscle atrophy after spinal isolation (activity-independent nerve influence) is less when compared to the atrophy caused by removal of all nerve influences by transecting the sciatic nerve [9]. Two basic mechanisms are responsible for denervation-induced muscle atrophy. First, there is augmented activity of the ubiquitin-proteasome pathway and proteolysis [48]. Second, there is cell death and myonuclei apoptosis conjugated with decreased capacity of satellite cell-dependent reparative myogenesis [49]. Together with atrophy, denervated/reinnervated muscles undergo phenotypical changes and conversion between muscle fiber types [50]. The 
relative increase in type I or type II muscle fibers following denervation seems to depend on the type of muscle fibers predominant in the muscle, with type II muscle fibers (fast fibers) increasing in proportion in soleus (considered a slow muscle) and type I muscle fiber number increasing in gastrocnemius and TA muscles [51]. Likewise, the degree of muscle fiber atrophy in short-term denervation (4 weeks) has been noticed to be greater in the muscle fiber type that is more abundant in the affected muscles [52]. Earlier studies suggested that it was possible that denervated muscles could have increased muscle plasticity due to acceleration in the early myoblastic stages of muscle regeneration. Nevertheless McGeachie and Grounds [53] data proved that very few precursors were proliferating in denervated muscle within $30 \mathrm{~h}$ after injury, and the onset of myogenesis at $30 \mathrm{~h}$ was essentially the same in denervated and innervated muscle. They compared the onset of DNA synthesis in muscle precursors in denervated and innervated muscle of adult BALBc mice regenerating after a simple cut injury. This study concluded that although denervation of skeletal muscles causes an increase in SCs and connective tissue cell turnover, it does not "prime" the general population of muscle precursors to start synthesizing DNA more rapidly after injury than in innervated muscle [53]. After sciatic nerve transection at an adult age, electromyography (EMG) patterns in hindlimb muscles during locomotion remained highly abnormal even after recovery periods lasting 15 or 21 weeks [54]. This may be a limitation when using denervated muscles as a model of muscle injury since regeneration might be affected for a very prolonged period. Like already mentioned, other models of skeletal muscle injury, like complete crush or myectomy, can be accompanied by denervation since these traumatic models may possibly damage peripheral nerves or myoneural junctions. This might also be an undesirable occurrence in the standardization of these models of muscle injury. In fact, our preliminary work using TA myectomy showed that few animals developed severe muscle force deficit after 4 weeks recovery, suggesting that damaged of the supplying nerve occurred in these animals subset.

In our research group, standard peripheral nerve injuries in the rat sciatic nerve model have been performed [57-63] in order to evaluate different therapeutic approaches including several biomaterials and cellular systems to promote sensitive and functional recovery of the nerve. A standard crush injury is performed by a non-serrated clamp (Institute of Industrial Electronic and Material Sciences, University of Technology, Vienna, Austria), exerting a constant force of $54 \mathrm{~N}$ for a period of 30s, 10mm above the bifurcation into tibial and common peroneal nerves, inducing a $3 \mathrm{~mm}$ axonotmesis lesion [57-63]. In order to induce a standard neurotmesis lesion in the rat sciatic nerve model, considered a more serious lesion, under deep anaesthesia, the right sciatic nerve is exposed through a skin incision extending from the greater trochanter to the distal mid-half followed by a muscle splitting incision. After nerve mobilisation, a transection injury is performed (neurotmesis) using straight microsurgical scissors. The nerve is injured at a level as low as possible, in general, immediately above the terminal nerve ramification. To prevent autotomy, a deterrent substance should be daily applied to rat right foot [57-63]. Both experimental injuries induce severe motor deficit and loss of sensory function, evaluated by measuring extensor postural thrust (EPT) and withdrawal reflex latency (WRL), respectively [57-63]. Sensory and motor deficit then progressively decreased along the post-operative, depending on the therapeutic approach used. 
Very promising results were obtained with chitosan type III membranes and MSCs isolated from the umbilical cord matrix. In addition, we also perform kinematic analysis of the rat walk which is a more sensitive behavioral test. This analysis is increasingly being used to assess functional recovery in peripheral nerve research because of its higher accuracy and better relationship with histological outcome [57-63]. We should bare in mind that locomotion is also of higher functional relevance since it involves integrated function of both the motor and sensory systems and their respective components, such as skeletal muscles, sensory endings, efferent and afferent nerve fibers and integrative centers within the central nervous system. Muscles innervated by sciatic nerve branches include both dorsiflexors and plantarflexors and, although in our published studies we focused our kinematic analysis only in the stance phase, we now prefer to include analysis of the ankle joint motion also during the swing phase in order to provide additional information [59]. Denervation can be a very useful model of skeletal muscle injury for some experimental studies but some limitations might be pointed out in studies that attempt to focus exclusively on the muscular regeneration process. Nevertheless and as demonstrated by several studies, this muscular regeneration process is highly dependent of the neural supply and the nerve regeneration itself can be influenced by the damaged muscle tissue.

\section{Tissue engineering and regenerative medicine}

Every day thousands of clinical procedures are performed to replace or repair tissues in the human body that have been damaged through disease or trauma that use tissue engineering technology. The use of constructs for tissue engineering (TE) and regenerative medicine are promising innovative therapies that can address several clinical situations. These constructs are often combination of cells, scaffolds and biological factors. Although there are only a few commercial products currently in the market for cell/drug delivery, probably because each type of cell requires its own specific encapsulating microenvironment with cell-specific material properties and spatially controlled bioactive features, a vast amount of research is being performed worldwide on all aspects of tissue engineering/regenerative medicine exploring polymer materials. To implant cells into defective skeletal muscles, there are two main techniques. The cellular system may be directly injected into the scaffold which is localized in the injury site. It can also be performed by pre-adding the cells to the scaffold via injection or co-culture (in most of the cellular systems, cells are allowed to form a monolayer) and then the biomaterial with the cellular system is implanted in the injured muscle. In case of multiple sites of injury, the systemic administration of cells capable of reaching damaged tissues would be an interesting alternative [64].

\section{1. - Scaffolds and Biomaterials}

Scaffolds, which are used to deliver cells, drugs, and genes into the body, can take on various forms from porous solid devices to injectable networks, such as a typical three-dimensional porous matrix, a nanofibrous matrix, a hydrogel, and microspheres. Although solid scaffold provide a mechanically strong matrix for seeded cells, hydrogel scaffolds and mi- 
crospheres are becoming increasingly popular in TE. The spherical nature maximizes the surface area, and the small volume of beads facilitating biomolecular transport. Regarding hydrogels, they have a similar microstructure to the extracellular matrix (ECM) and allow good physical integration into the defect by the use of minimally invasive approaches for material and cell/drug delivery. The biological, chemical, topography features and mechanical properties, as well as the degradation kinetics of hydrogels, can be tailored depending on the application [65-68]. Aligned nanoscale and microscale topographic features in scaffolds have been also reported to influence the alignment of cells. For example, this alignment is an important requirement of functional skeletal muscle since it leads to alignment of myoblasts and cytoskeletal proteins and promote myotube assembly along the nanofibres and microgrooves to mimic the myotube organization in muscle fibres [65, 68-70]. Scaffolds are used successfully in various fields of tissue engineering such as bone formation, periodontal regeneration, cartilage development, as artificial corneas, in tendon repair and in ligament replacement. In addition, the incorporation of drugs (i.e., inflammatory inhibitors and/or antibiotics) into scaffolds or specific molecules to provide adequate signals to the cells is also possible [71] Depending on the medical applications, scaffolds requirements will depend on its function. Hydrogels can be used as a physical barrier to protect the cells from hostile extrinsic factors before delivery, or be used as a matrix to drug controlled release or cell adhesion, growth and differentiation to further improve the secretion of therapeutic proteins from cells. In fact cells are capable of delivering drugs in response to an external stimulus, which is highly advantageous to maintain homeostasis for patients suffering from chronic diseases. For the first application, the scaffold needs:

i. to be biocompatible, by minimizing the patients' immune response, which is detrimental to cell viability, hydrogel stability, and mass transport. Ideally, the scaffold should evoke no or only minimal fibrous tissue reaction, macrophage activation, and cytokine and cytotoxic agent release

ii. to have controllable degradability, being the degradation products not toxic and eliminated easily from the implantation site by the body, and

iii. to have mechanical properties that are sufficient to shield cells from tensile forces without inhibiting biomechanical cues to cells through mechanotransduction pathways that mediate tissue homeostasis, morphogenesis, cell growth, contractility, differentiation, and pathophysiology [70-72].

For the second applications further requirements are needed, mainly:

i. a microstructure that allows for the influx of nutrients and oxygen toward the encapsulated cells and prevents the efflux of therapeutic molecules and cellular wastes away from the scaffold; this is assured through adequate pore size distribution and its interconnectivity. A high surface:volume ratio should be suitable for cell/drug attachment;

ii. adequate drug binding affinity to allow a controllable drug released to be stable when incorporated in the scaffold at a physiological conditions; 
iii. bioadhesion, to allows cells and tissues to adhere to scaffolds. Some hydrogels such as fibrin or collagen inherently exhibit bioadhesive properties, but others do not and therefore linker molecules that enable covalent or non-covalent molecular interactions between the scaffold and its surroundings are incorporated;

iv. the mechanical properties of the scaffold, commonly controlled with the polymer concentration and molar ratio between polymers and cross-linking molecules, should match those of the tissue at the implantation site as well as the degradation rate that should match the rate of tissue regeneration [73-77].

\subsubsection{Hydrogel scaffolds}

Hydrogels, three-dimensional (3D) networks of hydrophilic polymers, are appealing for biological applications because of their high water content, high permeability, biocompatibility, and the ability of be placed into critical defects in a minimally invasive manner [78]. They are being used in a wide range of tissues, including cartilage, bone, muscle, fat, liver, and neurons. For use in drug/cell delivery, hydrogels should be low-viscosity solutions prior to gelling, which is crucial to maintain cell viability during the encapsulation process, and should rapidly gel in the human body. These properties can be fine-tuned through variations in the chemical structure and cross-linking density in hydrogels. Injectable hydrogels can be formed in situ by either chemical or physical cross-linking methods [79, 80]. Physical cross-linked hydrogels are capable of phase transition in response to external stimuli such as temperature, $\mathrm{pH}$ or both [81]. Chemically cross-linked hydrogels are prepared through photopolymerization, disulfide bond formation, or reaction between thiols and acrylate or sulfone. The latter hydrogels undergo significant volume changes compared to the first ones [81-83]. The $\mathrm{pH} /$ temperature-sensitive hydrogels show several advantages over thermo-sensitive ones, such as the absence of clogging during injection and avoidance of $\mathrm{pH}$ decreased caused by degradation. The $\mathrm{pH} /$ temperature-sensitive copolymer hydrogels can be prepared by combining a $\mathrm{pH}$-sensitive moiety with a temperature-sensitive block. For example, if acidic sulfamethazine oligomers (OSMs) are coupled with thermosensitive poly(e-CL-coLA)-PEG-poly-(e-CL-co-LA) triblock copolymers a $\mathrm{pH} /$ temperature-sensitive hydrogels (OSM-PCLA-PEG-PCLA-OSM) is produced. Photopolymerized hydrogel systems have been reported to provide better temporal and spatial control over the gelation process [79, 81, 84].

\subsubsection{Biomaterials for scaffold fabrication}

A wide variety of natural and synthetic materials have been used to prepare injectable hydrogels. Natural polymers, which are either components of or have macromolecular properties similar to the natural ECMs, are known to often undergo rapid degradation upon contact with body fluids or medium and show batch-to-batch variation. Synthetic hydrogels offer improved control of the matrix architecture and chemical composition, no immunogenicity, consistent supply of large quantities, but tend to have lower biological activity. Therefore, modification of natural and synthetic derived hydrogels is usually required [79]. A natural biodegradable 3D scaffold can be made of acellular muscle ECM but it's fragile and difficult to handle [85]. Another natural biodegradable scaffold can be created by using 
fibrin, which leads to a process much similar to wound healing, in which fibrin forms a temporary scaffold to serve tissue regeneration and then is replaced by the physiological ECM. Fibrin has the additional advantage that it binds growth factors [70].

Fibrin hydrogels are made from commercially purified allogeneic fibrinogen and purified thrombin, and have been used in a variety of tissue engineering applications. Its main disadvantages reported to be shrinkage of the gel, low mechanical stiffness and its rapid degradation can be overcome by incorporating other polymers such as gelatin, hyaluronic acid, and chondroitin-6-sulfate. Fibrin glue is clearly distinguished from fibrin hydrogels that are prepared from purified fibrinogen and thrombin. Despite the commercial fibrin glue is available in standardized quality; autologous fibrin glue is cheaper and has no viral transmission and prion infection [86]. Tisseel ${ }^{\circledR} \mathrm{VH}$, is a fibrin glue commercialized by Baxter, and consists of a two-component fibrin biomatrix with highly concentrated human fibrinogen to produce fibrin gel from a blood sample and is safe to be used in TE. FloSeal ${ }^{\circledR}$ is another commercial hemostatic matrix with potential in TE, and consists of a cross-linked bovine-derived Gelatin Matrix component and a human-derived Thrombin component. Literature reports that myoblasts seeded on fibrin gels have been shown to differentiate into contracting muscle fibres and to demonstrate a normal length-tension and force-frequency relationship [87, 88].

Alginate is the designation given to a natural family of biodegradable, biocompatible, hydrophilic and non-toxic polysaccharides extracted from some marine algae and some microorganisms. Alginates are linear block co-polymers composed of two different monomers, $\beta$ D-mannuronic acid (M) and $\alpha$-L-glucuronic acid $(\mathrm{G})$, which are linked by (1-4) glycosidic bonds. The main property of alginate that potentiates its use in different areas, it is its ability to bind some divalent cations such as $\mathrm{Ca}^{2+}$ in the carboxylic groups which provides the gelation of the alginate solution. The properties of the gel are dependent of the ratio between $\mathrm{M}$ and $\mathrm{G}$ monomers (M:G ratio); if the proportion of the $\mathrm{G}$ monomer is predominant, a strong brittle gel it obtained, whereas if the proportion of the M monomer is predominant, the formed gel will be weaker, but more flexible, because there are less junction zones between the polymer chains. As alginate is a polyelectrolyte, more specifically a polyanion, it can be ionically associated with a polycation existent in the same solution through hydrogen bonding or electrostatic interactions, forming a polyelectrolyte complex [89, 90]. Cell-encapsulating calcium cross-linked alginate hydrogels have been extensively studied because alginate molecules are anionic polysaccharides and do not associate with many proteins. Since alginate itself is inert for cell attachment and spreading, the cell adhesion properties can be tailored by linking molecules such as RGD peptides to its backbone [91].

Chitosan is a natural and hydrophilic copolymer, and it is composed by two monomeric units, D-glucosamine and N-acetyl-D-glucosamine linked by $\beta(1-4)$-glycosidic bond. This linear polysaccharide has been widely studied in medical applications due to its biocompatibility, biodegradability, non-toxicity, fungistaticity, antimicrobial activity, non-carcinogenicity, notable affinity to proteins, promotion of cell adhesion as well as proliferation and differentiation [67]. Chitosan results from the alkaline deacetylation of the chitin and its solubility is mainly influenced by its molecular weight and degree of deacetylation. Some methods have been developed to lower the molecular weight of chitosan by hydrolysis of 
the polymeric chains, in order to produce chitosan salts which are soluble in water. Chitosan-based hydrogels have been gelled via glutaraldehyde cross-linking, UV irradiation, and thermal variations [81].

Hyaluronic Acid (HA) is a natural, hydrophilic and non-sulfated glycosaminoglycan. This polymer is a linear polysaccharide, in which the repeating unity is a disaccharide composed by two monomers, D-glucuronic acid and N-acetyl-D-glucosamine, linked through alternating $\beta 1,3$ and $\beta 1,4$ glycosidic bonds. HA has been used as a biomaterial in various medical applications, due to its biocompatibility, biodegradability, and non-immunogenicity. HA is the main component existent in the extracellular matrix (ECM) of living tissues, namely in the connective, epithelial and neural. This polymer, due to its structural and biological properties, has the ability of mediate the cell signalling and behaviour, and the matrix organization. HA is able of interact with some cell surface receptors, being involved in the tissue hydrodynamics, cell migration and proliferation. Several strategies have been reported to prepare HA-based hydrogels [92, 93].

Among the most widely used synthetic polymers for scaffolds, either alone or copolymerized with synthetic or natural polymers, as biodegradable polymers are polyglycolide, polylactide and its copolymer poly(lactide-co-glycolide), polyphosphazene, polyanhydride, poly(propylene fumarate), polycyanoacrylate, polycaprolactone, polydioxanone, and polyurethanes, and as non-biodegradeable polymers are included polyvinyl alcohol (PVA), polyhydroxyethymethacrylate, and poly(N-isopropylacrylamide) [71, 94].

The majority of natural biomaterials used in clinical applications are derived from animal or human cadavers' sources. In spite of thorough purification methods, these materials bear the inherent risk of transfer viral diseases and may cause immunological body reactions while synthetic biomaterials are not associated with these risks. So, a critical issue in this type of cellular transplants is the search for an optimal vehicle to provide the ideal environment for cell hosting and for the release and conduction of molecules to the site of injury for cell-host interaction. Taking this into account we evaluated different biomaterials as vehicles for the cellular system intended to be tested for skeletal muscle regeneration using our myectomy injury model in the rat. Plasma derived substances, hemostatic matrix solutions and hydrogels (Figure 2 and Figure 3) were tested and the in vivo response was compared histologically according to the International Standard ISO 10993-6 (see 5.1.3). The following procedure was done under sterile conditions. For preparation of the spherical hydrogel, the polymer solution is prepared by adding in a ratio of $1: 1(\mathrm{~V} / \mathrm{V})$, a sodium alginate aqueous solution $7 \%(\mathrm{~m} / \mathrm{V})$ to a sodium hyaluronate aqueous solution $0.5 \%(\mathrm{~m} / \mathrm{V})$, under magnetic stirring. Afterwards the polymer solution is inserted into an insulin syringe and a droplet is released into an excess of cerium nitrate solution $135 \mathrm{mM}$, in order to obtain a cross-linked polymer sphere of approximately $60 \mu \mathrm{l}$ of volume. Cerium nitrate and sodium hyaluronate solution were sterilized by microfiltration $(0.22 \mu \mathrm{m}$ membrane) and sodium alginate powder is sterilized in an autoclave $\left(120^{\circ} \mathrm{C}\right.$ for 15 minutes) previous to the solution preparation (Figure 2 and Figure 3). These tested biomaterials including the spherical hydrogel were not only used as vehicles but their properties were also evaluated and optimized to find a suitable matrix for the cellular implants. 


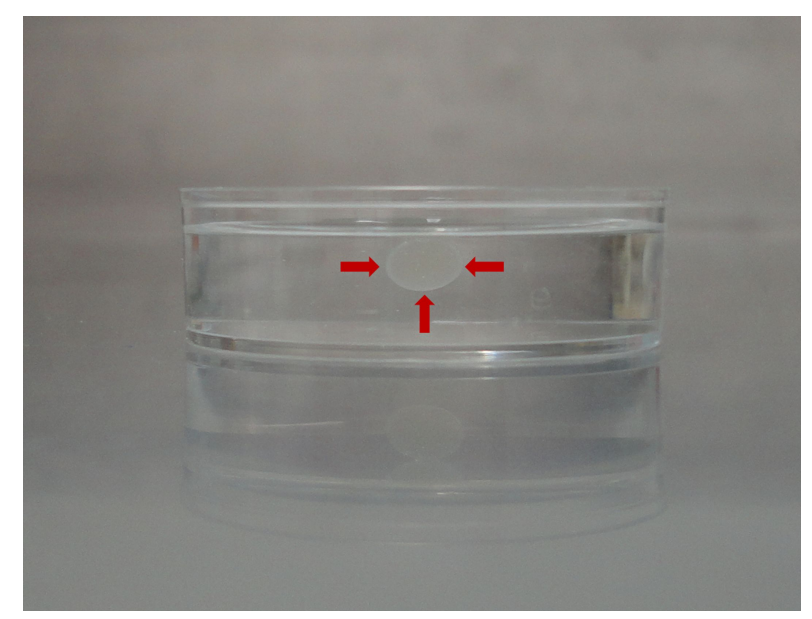

Figure 2. Hydrogel preparation (alginate, hyaluronic acid and cerium).

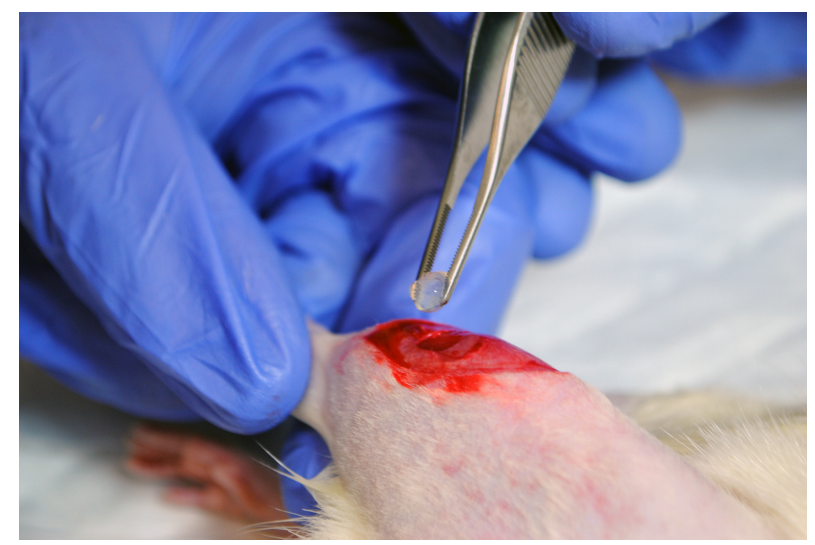

Figure 3. Application of a spherical hydrogel containing $1 \times 10^{6} \mathrm{MSC}$ from the Wharton's jelly, in the 5 mm $\varnothing$ TA myectomy defect.

\subsection{Cells}

There is evidence both from animal studies and clinical investigations that cell therapy involving different types of stem cells application is promising as means to promote regeneration of skeletal muscles following severe injuries. Technical or/and ethical difficulties in obtaining sufficient and appropriate stem cells from the bone marrow or from embryos (obtained from assisted reproduction techniques or somatic nuclear transfer - cloning) have limited the application of this type of therapy. Stem cells are known as an undifferentiated 
population, with endless self-renewal and sustained proliferation in vitro and multilineage differentiation ability [95]. The in vitro multilineage differentiation is the concept that gives these cells an extreme priority for use in tissue and cell-based therapies. Stem cells can be loosely classified into 3 categories based on their functional role: hematopoietic stem cells, mesenchymal stem cells (MSCs) and embryonic stem cells [95].

MSCs have become one of the most exciting targets for tissue regeneration due to their high plasticity, proliferative and multilineage differentiation capacity. These cells are capable of differentiating into adipose, bone cartilage and muscle. Among all this notable characteristics, MSCs reveal other properties of great importance, they present low immunogenicity and high immunosuppressive properties due to a decreased or even absence HLA Class II expression [96]. Differentiation potential of MSCs in multilineage end-stage cells has been proven, so as the treatment potential in musculoskeletal disorders [97, 98]. Since their first isolation in 1968, from rat bone marrow [99], MSCs have been isolated with success from almost all tissue sources: skeletal muscle, adipose tissues, synovial membranes, umbilical cord matrix and blood, placental tissue, amniotic fluid among others. Along with differentiation capacity, an increasing amount of data has demonstrated that the MSCs have the capacity of modulating the surrounding environment, by secretion of multiple factors and activation of endogenous progenitor cells [100, 101].

\subsubsection{Umbilical cord}

From our data and from previously published experimental work, the development of cell therapies associated to biomaterials is a promising tool for increase skeletal muscle regeneration, avoiding the irreversible loss of function and limit the fibrous scar tissue presence [57-59]. Recent years have witnessed an explosion in the number of adult stem cells populations isolated and characterized. While still multipotent, adult stem cells have long been considered restricted, giving rise only to progeny of their resident tissues. Recently, and currently controversial studies have challenged this dogma, suggesting that adult stem cells may be far more plastic than previously appreciated [102, 103]. Extra-embryonic tissues as stem cell reservoirs offer many advantages over both embryonic and adult stem cell sources. The umbilical cord matrix is an important and safe source of MSCs with positive effects in nerve and skeletal muscle regeneration, with no ethical or technical issues. MSC isolated from umbilical cord matrix (Wharton's jelly), as well as embryonic stem cells (ESCs) are originated from inner cell mass of blastocyst [104]. Comparing with ESCs, MSCs have shorter population doubling time; can be easily cultured in plastic flasks, are well tolerated by immune system; therefore transplantation of these cells into non-immune-suppressed animals does not induce acute rejection. Most important, these cells do not originate teratomas [104]. Like bone marrow stromal cells and other MSCs, the MSCs from the Wharton's jelly are plastic adherent, stain positively for markers of the mesenchymal lineage (CD10, CD13, CD29, CD44, CD90, and CD105) and negatively for markers of the hematopoietic lineage. These MSCs are capable of self-renewal with sustained proliferation in vitro and can differentiate into multiple mesodermal cells. The high plasticity and low immunogenicity of these cells turn them into a desirable form of cell therapy for the injured musculoskeletal tissue 
without requiring the use of immunosuppressive drugs during the treatments. Interestingly, these cells, which are HLA class II negative, not only express both an immuno-privileged and immuno-modulatory phenotype, but their HLA complex class I expression levels can also be manipulated, making them a potential cell source for MSC-based therapies. In addition and as previously referred, these cells represent a non-controversial source of primitive mesenchymal progenitor cells that can be harvested after birth, cryogenically stored, thawed, and expanded for therapeutic uses. MSCs from the Wharton's jelly display a high proliferative rate and plasticity, being able to differentiate into adipocytes, osteoblasts, chondrocytes, cardiomyocites, neurons, and glia. More recently, Conconi et al. [105] demonstrated that CD105(+)/CD31(-)/KDR(-) cells are able not only to differentiate in vivo towards the myogenic lineage as demonstrated by the co-localization of HLA 1 and sarcomeric tropomyosine antigens, but also to contribute to the muscle regenerative process. These cells were found to differentiate in vitro into myoblast-like cells, expressing Myf5 and MyoD after 7 and 11 days of myogenic induction, respectively. The timing of expression of Myf5 and MyoD in CD105(+)/CD31(-)/KDR(-) cells is similar to that described during embryonic development and in myoblast cultures [105].

Using the myectomy model we tested the use of Human MSCs isolated from the Wharton's jelly in order to improve skeletal muscle regeneration. The cells were directly infiltrated into the lesion or delivered by different vehicles including Floseal ${ }$, Tisseel ${ }^{\circ}$, carboximetilcellulose (Sigma) and spherical hydrogel (own fabrication). MSC from Wharton's jelly were purchased from PromoCell GmbH (C-12971, lot-number: 8082606.7). The MSCs are cultured and maintained in a humidified atmosphere with $5 \% \mathrm{CO}_{2}$ at $37^{\circ} \mathrm{C}$. Mesenchymal Stem Cell Medium, PromoCell (C-28010) is replaced every 48 hours. At 90\% confluence, cells are harvested with $0.25 \%$ trypsin with EDTA (GIBCO) and passed into a new flask for further expansion. MSCs at a concentration of $2 \times 10^{5}$ cells are cultured exhibiting a $90 \%$ confluence after 3-4 days. The application of human MSCs in rats is possible without inducing any immunossupression in the experimental animals. The MSCs exhibited a normal star-like shape with a flat morphology in culture (Figure 4). A total of 20 Giemsa-stained metaphases of these cells, were analyzed for numerical aberrations. Sporadic, non-clonal aneuploidy was found in 3 cells (41-45 chromosomes) the other 17 metaphases had 46 chromosomes. The karyotype was determined in a completely analyzed G-banding metaphase and no structural alterations were found [57]. The karyotype analysis to the MSCs cell line derived from Human Wharton jelly demonstrated that this cell line hasn't neoplasic characteristics and is stable during the cell culture procedures in terms of number and structure of the somatic and sexual chromosomes. Also, the morphologic characteristics of these cells in culture, observed in an inverted microscope, are normal. These cells presented a star-like shape with a flat morphology, characteristic of the MSCs been adequate to be used in in vivo rat experimental model [57]. The MSCs karyotype was studied in order to be sure that these cells did not present any number or structure chromosome abnormalities due to isolation and cell culture procedures before in vivo application. This concern was due to the negative effects that some cellular systems, like the ESCs present, inducing the production of teratomas. The cellular systems implanted into the injured skeletal muscle improved the skeletal muscle re- 
generation since these cells produce growth factors, ECM molecules, and even modulate the inflammatory process.

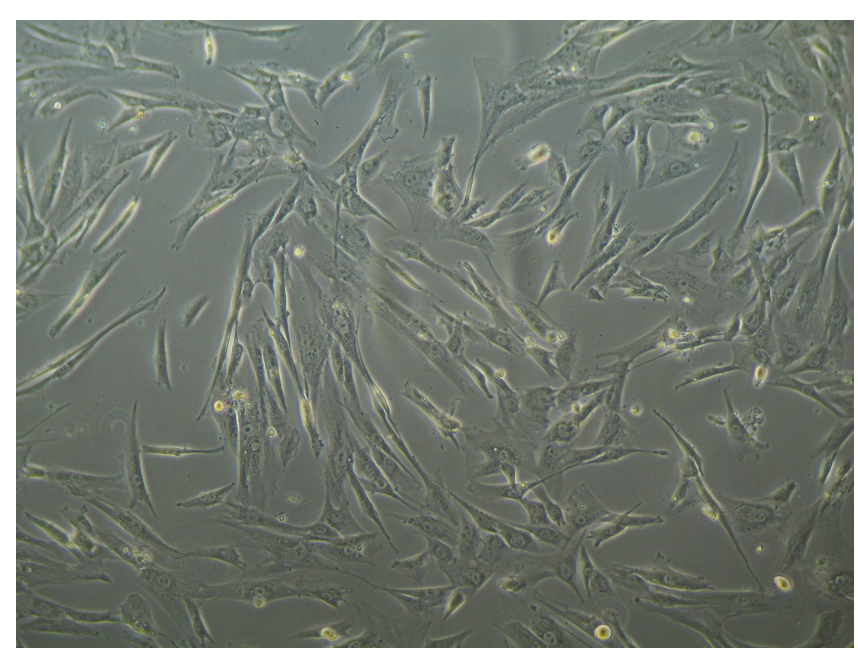

Figure 4. Undifferentiated MSCs from Wharton's jelly, exhibiting a star-like shape with a flat morphology (100x magnification).

\section{Evaluation of muscle regeneration}

Muscle biopsies should be considered in order to obtain careful clinical assessment or for investigation purposes. After the collection of the muscle samples, they should be immediately equally divided in three. One sample should be placed into formalin (for hematoxilin and eosin - HE), another sample should be fixed into $2.5 \%$ purified glutaraldehyde in $0.1 \mathrm{M}$ Sorensen phosphate buffer (for electron microscopy - EM) and the other sample should remain unfixed and refrigerated (for histochemistry, biochemistry/genetics analysis).

\subsection{Routine histological evaluation}

Routine evaluation of the muscle biopsy sample involves the examination of formalin-fixed, paraffin processed sections and unfixed frozen sections with standard histological and enzyme histochemical stains at the light microscopic level. HE is the routine histological stain used for evaluation of basic tissue organization and cellular structure. For HE, the whole piece of tissue should be fixed in a clamp and after the tissue is infiltrated with wax, both longitudinal and cross sections must be cut before embedding. Five levels should be obtained, especially in cases suspected of vasculitis. The parameters that can be evaluated are: the type of inflammatory infiltrate present; examination of the structure of vessels walls (vasculitis and/or fibrinoid necrosis); presence of endomysial and perimysial fibrosis/fatty 
infiltration; the range of fiber caliber; presence of angulated fibers; increase in number of centrally located nuclei; central capillary migration; split fiber; group atrophy; necrotic/ myopathic (degenerating) fibers; atrophic fibers; regenerating fibers; target fibers; whorl fibers and ring fibers. The rounding of fiber contour and the variation of fiber diameter should also be analyzed, however they are better evaluated with frozen sections (Figure 5).

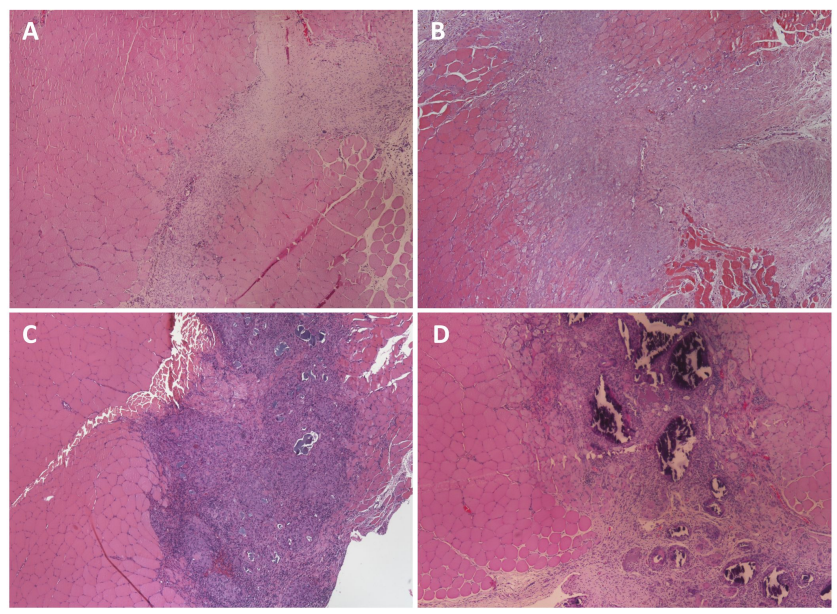

Figure 5. HE staining of TA muscles 15 days post myectomy (A - control) and application of fibrin (B), hydrogel (C), Floseal $^{\circ}(\mathrm{D})$.

\subsubsection{Morphological analysis}

Long-standing histological characteristics are still used to identify the mammalian skeletal muscle regeneration process. On muscle cross-sections, these fundamental morphological characteristics are newly formed myofibers of small caliber and with centrally located myonuclei. Newly formed myofibers are often basophilic (reflecting high protein synthesis) and express embryonic/developmental forms of MHC (reflecting de novo fiber formation). On muscle longitudinal sections and in isolated single muscle fibers, central myonuclei are observed in discrete portions of regenerating fibers or along the entire new fiber, suggesting that cell fusion is not diffuse during regeneration but rather focal to the site of injury [1]. Cross-sectional area (CSA) analysis is one of the features that can be assessed. This can be achieved with imaging software processing (Scio Image, ImageJ) of HE-stained muscle sections. A predefined number of fibers is traced per sample and should be determined as appropriate by the examination of no additional changes in standard deviation. The classification of small and large fibers can be determined for example by setting three standard deviations from the mean CSA for the uninjured group at different time points [14]. The CSA and number of myotubes can be used to estimate the development degree of muscle regeneration following injury [36]. 


\subsubsection{Collagen quantification}

Collagen content in the wound bed can be calculated by image analysis of Masson's Trichrome-stained histological images taken at a predefined image magnification. Color separations must be performed and an analysis threshold must be established for each image series collected using the same brightness and white balance settings. Output images showing only computed blue coverage must be compared to the color images to ensure the representation of truly blue color due to collagen staining. As a control the analysis must be performed on uninjured (control) skeletal muscle tissue sections stained with Masson's Trichrome and collected using the same camera and threshold settings to confirm a collagen content of zero for control tissue. The ratio of blue pixels above the threshold to total pixels in the image is used to calculate the collagen content for each image [40].

\subsubsection{International Standard (ISO 10993-6)}

The International Standard (ISO 10993-6) specifies test methods for the assessment of the local effects after implantation of biomaterials intended for use in medical devices. These implantation tests are not intended to evaluate or determine the performance of the test specimen in terms of mechanical or functional loading. The local effects are evaluated by a comparison of the tissue response caused by the tested implant to that caused by the control. The objective of the test methods is to characterize the history and evolution of the tissue response after implantation of a medical device/biomaterial including final integration or resorption/degradation of the material. The test sample shall be implanted into the tissues most relevant to the intended clinical use of the material. For short-term testing, animals such as rodents or rabbits are commonly used. During the first two weeks after implantation the reaction due to the surgical procedure itself may be difficult to distinguish from the tissue reaction evoked by the implant and for that reason in our study we collected the muscle samples 15 days after implantation. For degradable/resorbable materials the test period shall be related to the estimated degradation time of the test product. In our case the majority of the vehicles/matrices tested the degradation time is less than 4 days. In the absence of complete degradation, absorption, or restoration to normal tissue structure and function, the overall data collected may be sufficient to allow characterization of the local effects after implantation. A sufficient number of implants shall be inserted to ensure that the final number of specimens to be evaluated will give valid results. The evaluation of the biological response must be accomplished by documenting the macroscopic and histopathological responses as a function of time. The responses to the test sample must be compared to the responses obtained at the control sample or sham operated sites. The scoring system used for the histological evaluation shall take into account the extent of the area affected, either quantitatively (e.g. in micrometres) or semi-quantitatively (Annex E of this Standard) [44, 106]. The biological response parameters, which shall be assessed and recorded, include:

i. the extent of fibrosis/fibrous capsule (layer in $\mu \mathrm{m}$ ) and inflammation;

ii. the degeneration as determined by changes in tissue morphology; 
iii. the number and distribution as a function of distance from the material/tissue interface of the inflammatory cell types, namely polymorph nuclear neutrophilic leucocytes, lymphocytes, plasma cells, eosinophils, macrophages and multinucleated cells;

iv. the presence, extent and type of necrosis;

v. other tissue alterations such as vascularization, fatty infiltration, granuloma formation and bone formation;

vi. the material parameters such as fragmentation and/or debris presence, form and location of remnants of degraded material;

vii. the quality and quantity of tissue ingrowth, for porous and degradable implant materials [106].

Under the conditions of the study and following the results for the mentioned parameters in the semi-quantitative scoring system (Annex E of this Sandard), the test sample is considered as non-irritant $(0,0$ up to 2,9$)$, slight irritant $(3,0$ up to 8,9$)$, moderate irritant $(9,0$ up to $15,0)$, severe irritant $(>15)$ to the tissue as compared to the negative control sample [106]. This test method is used for assessing the biological response of muscle tissue to an implanted material (Annex C of this Standard). As already mentioned, the method compares the biological response to implants of test specimens with the biological response to implants of control specimens. The control materials are those used in medical devices of which the clinical acceptability and biocompatibility characteristics have been established [106]. In our study we developed an adaptation of this Standard by considering the control as the group where the surgical procedure (myectomy) was performed without any biomaterial or cell implantation (Figure 6). Although the surgical technique may profoundly influence the result of any implantation procedure, we assumed that our standardized myectomy lesion could be considered as the Control group since we were able to determine the local effects of the different implants by their comparison to the minor effects of the surgical procedure. The surgeries were executed under general anesthesia with a xylazine $(1.25 \mathrm{mg} / 100 \mathrm{~g}$ BW $\mathrm{im}$ ) and ketamine (9 mg/100 g BW im) combination [38].

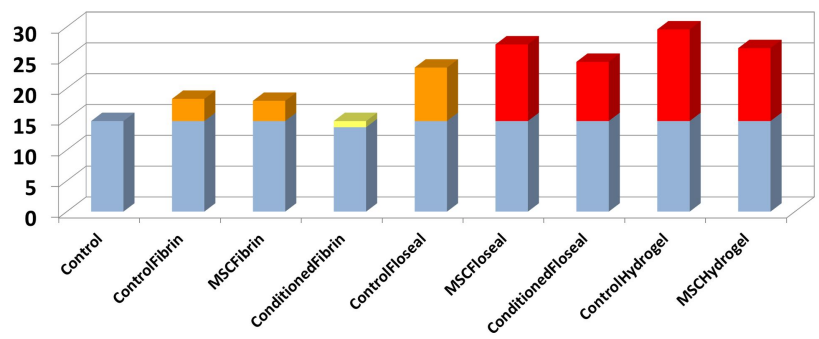

Figure 6. ISO 10993-6 scoring for the groups tested. The Contro/ group obtained a score of 14.7 (in blue). Scorings above the Control group were considered as non-irritant (in yellow), slight irritant (in orange) and moderate irritant (in red). 


\subsection{Histochemistry}

For histochemistry a basic panel should be performed, preferentially in frozen sections. Depending on the objectives, an extended panel can be done concerning the study of some molecules like the already mentioned Masson's Trichrome-stain or enzyme processes such as ATPase; NADH-TR or Esterase (Bancroft\&Stevens). When necessary, other special stains can be performed on paraffin sections.

\subsection{Immunohistochemistry}

In general, the immunohistochemical stains are utilized for the diagnosis of various muscular dystrophies. They also may help to determine the subtypes of inflammatory cells within an infiltrate or for other investigation purposes. Specific skeletal muscle markers such as myosin heavy chain and desmin can be applied in order to clearly identify this tissue. The distinction of SCs, considered as the reservoir of myogenic precursor cells, from other cells must be made (like plasma cells, which may be occasionally seen under the basal lamina in pathologic conditions). SCs can be easily demonstrated by immunostaining for N-CAM; they also express vimentin. Activated SCs generally express Myo-D and myogenin [107]. The regenerating fibers express N-CAM, MyoD and myogenin, and also embryonic and neonatal isoforms of myosin heavy chain. In contrast to mature fibers, $\mathrm{MCH}$ class I histocompatibility complex is expressed in regenerating fibers.

\subsection{Immunofluorescence}

For the preparation of TA muscles for immunofluorescence they should be embedded in Tissue-Tek OCT compound. Sections are cut at $10 \mu \mathrm{m}$ using a Leica CM1850 cryostat and placed onto Surgipath microscope slides. Laminin- $\alpha 2$ chain is detected with a 1:500 dilution of rabbit anti-laminin- $\alpha 2(2 \mathrm{G})$ polyclonal antibody. The laminin- $\alpha 1$ chain is detected with a rat anti-laminin- $\alpha 1$ monoclonal antibody. Primary rabbit antibodies are detected with a 1:500 dilution of fluorescein isothiocyanate-conjugated anti-rabbit secondary antibody and the rat monoclonal antibody is detected with 1:500 dilution of fluorescein isothiocyanateconjugated anti-rat secondary antibody. In all immunofluorescence experiments, secondary only antibody controls are included to test for specificity. For mouse monoclonal antibodies, endogenous mouse immunoglobulin is blocked with a mouse-on-mouse (MOM) kit. A $1-\mu \mathrm{g} / \mathrm{ml}$ concentration of tetramethylrhodamine-conjugated wheat germ agglutinin (WGA) is used to define muscle fibers. To examine immune response, cytotoxic $\mathrm{T}$ cells are detected with fluorescein isothiocyanate-labeled rat anti-mouse CD8a and macrophages are detected with fluorescein isothiocyanateconjugated anti-mouse F4/80 at 1:1000 (Figure 7 and Figure 8) [50]. 


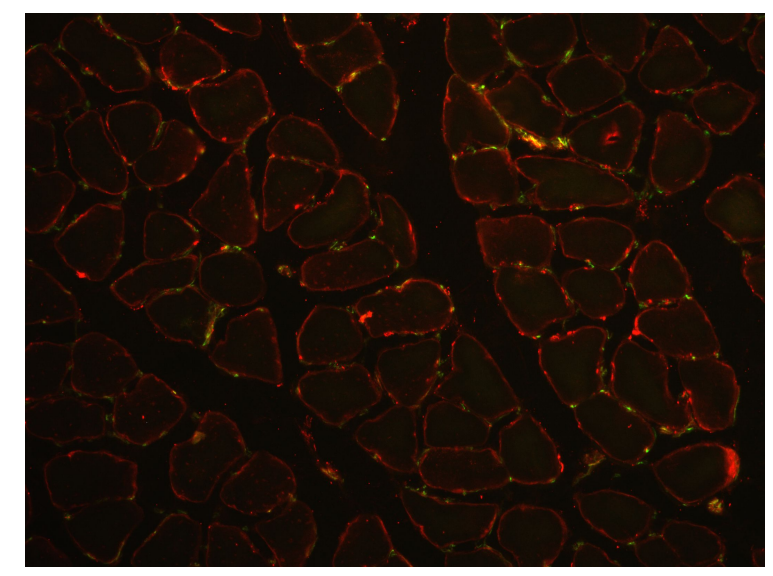

Figure 7. Double imunofluorescence staining for laminin and CD31.

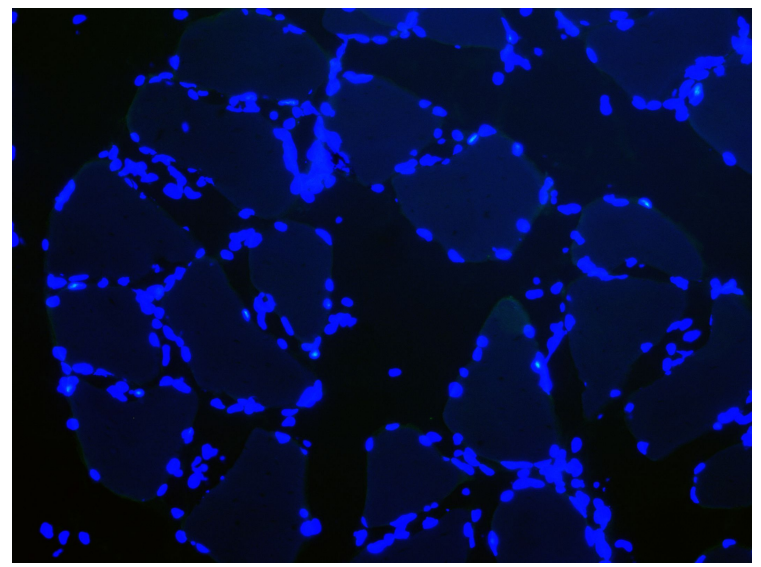

Figure 8. $\mathrm{Pax} 7^{+} \mathrm{SC}$ counterstained with DAPI.

\subsection{Electron microscopy}

Electron microscopic (EM) examination of the glutaraldehyde-fixed portion of the biopsy is performed when the light microscopic studies are inconclusive. Thus, it is reserved for selected circumstances in which the pathologist determines that EM has the potential of contributing significantly to determining a specific diagnosis. A specimen placed in glutaraldehyde must be small, approximately 1-2 $\mathrm{mm}$ in width and depth, allowing the complete tissue penetration by this fixative. Glutaraldehyde makes tissue brittle and interferes with immunohistochemical studies, so it is not appropriate for the paraffin specimen. With EM, other muscle cell parameters can be analyzed in detail: the myofibril architecture; 
the plasma and sarcolemmal membrane; the mitochondria (size, density and shape); T-tubule; amount of lipid; nucleus; phagocytic granules and amount of glycogen. EM is extremely useful in some cases: to identify inclusions primarily found by light microscopy; to help in the characterization of stored material found on light microscopy and define its intracellular localization; to analyze structural abnormalities found by light microscopy; can assist in the diagnosis of mitochondrial myopathy or seeking evidence to support a diagnosis of dermatomyositis (EM can be used to look for tubuloreticular inclusion in endothelial cells when light microscopic fails to reveal it).

\subsection{Contraction force measurement}

To obtain an estimate of total TA muscle strength reduced by the injury and possibly recovered by the cell/vehicle implants, contractile force due to electrical stimulation can be measured before injury, after injury and at the time of sacrifice (at different time points) for nonimplanted and implanted animals. This can be accomplished with the animals under general anesthesia and by anchoring the knee joint using a custom clamping system anchored to the floor of the surgical stereomicroscope stand and attaching a silk ligature to the cleft between digits 1 and 2 that must be anchored to a transducer at the other end. This can also be executed by cutting the TA tendon just before the insertion at the ankle and tying it with a 4.0 nylon suture attached to the isometric transducer. The exposed muscle is stimulated using 2 custom needle electrodes placed at the proximal muscle surface. Electrical stimulation of the TA muscle is applied at 5 volts, $4 \mathrm{~ms}$ pulse duration, at $500 \mathrm{~ms}$ intervals and the resultant tetanic force recorded (200 points(s) using a BioPac MP-100 (Harvard Apparatus) and accompanying software (Acknowledge ${ }^{\mathrm{TM}}$ ). The muscle must be kept hydrated during the procedure using sterile saline. Maximum tetanic force is measured by reducing the stimulation interval to $20 \mathrm{~ms}$, generating continuous stimulation simulating tetanus condition. Another method of applying the electrical stimulation can be obtained by exposing the sciatic nerve with an incision in the hamstring region The tibial nerve is cut just after the sciatic nerve splits into the tibial and peroneal nerves to eliminate any contraction from the gastrocnemius muscle causing background in the force data. The exposed sciatic nerve is then laid over two electrodes with a small piece of parafilm and should also be kept moist with periodic treatment of mineral oil. Stimulation is made using a supra-maximal square-wave pulse of $0.1 \mathrm{~ms}$ duration. Measurements are performed at the length at which maximal extension is obtained during the twitch and the data should be recorded for sub-maximal and maximal isometric force. Specific maximal force should be quantified by correcting for muscle mass $[40,98]$.

\section{Acknowledgements}

The authors would like to thank the support by Dr. José Manuel Correia Costa, from INSRJ, Porto, Portugal; and Biosckin, Molecular and Cell Therapies SA for the umbilical cord units supply and access to the GMP cell culture room (Scientific Protocol between Porto University and Biosckin, Molecular and Cell Therapies SA). This work was supported by Fundação 
para a Ciência e Tecnologia (FCT), Ministério da Ciência e Ensino Superior (MCES), Portugal, through the financed research project PTDC/DES/104036/2008, and by QREN № 1372 para Criação de um Núcleo I\&DT para Desenvolvimento de Produtos nas Áreas de Medicina Regenerativa e de Terapias Celulares - Núcleo Biomat \& Cell. A Gärtner (SFRH/BD/ 70211/2010) and I Amorim (SFRH/BD/76237/2011) acknowledge FCT for financial support.

\section{Author details}

Tiago Pereira ${ }^{1,3^{*}}$, Andrea Gärtner ${ }^{1,3}$, Irina Amorim ${ }^{3}$, Paulo Armada-da-Silva ${ }^{2}$, Raquel Gomes ${ }^{1,3}$, Cátia Pereira ${ }^{2}$, Miguel L. França ${ }^{1,3}$, Diana M. Morais ${ }^{4}$, Miguel A. Rodrigues ${ }^{4}$, Maria A. Lopes ${ }^{4}$, José D. Santos ${ }^{4}$, Ana Lúcia Luís ${ }^{1,3}$ and Ana Colette Maurício 1,3

*Address all correspondence to: tiago.vet@gmail.com

1 Centro de Estudos de Ciência Animal (CECA), Instituto de Ciências e Tecnologias Agrárias e Agro - Alimentares (ICETA), Universidade do Porto (UP), Portugal

2 Faculdade de Motricidade Humana (FMH), Universidade Técnica de Lisboa (UTL), Portugal

3 Instituto de Ciências Biomédicas Abel Salazar (ICBAS), Universidade do Porto (UP), Portugal

4 CEMUC, Departamento de Engenharia Metalúrgica e Materiais, Faculdade de Engenharia, Universidade do Porto (FEUP), Portugal

\section{References}

[1] Charge, SBP, \& Rudnicki, M. A. (2004). Cellular and molecular regulation of muscle regeneration. Physiological Reviews, 84(1), 209-38.

[2] Gibson, M. C., \& Schultz, E. (1982). The distribution of satellite cells and their relationship to specific fiber types in soleus and extensor digitorum longus muscles. Anat Rec, 202(3), 329-37, Epub 1982/03/01.

[3] Snow, M. H. (1983). A quantitative ultrastructural analysis of satellite cells in denervated fast and slow muscles of the mouse. Anat Rec, 207(4), 593-604, Epub 1983/12/01.

[4] Pette, D., \& Staron, R. S. (2000). Myosin isoforms, muscle fiber types, and transitions. Microscopy research and technique, 50(6), 500-9, Epub 2000/09/22.

[5] Huxley, A. F. (2000). Cross-bridge action: present views, prospects, and unknowns. Journal of biomechanics, 33(10), 1189-95, Epub 2000/07/19. 
[6] Carlson, B. M., \& Faulkner, J. A. (1983). The regeneration of skeletal muscle fibers following injury: a review. Medicine and science in sports and exercise, 15(3), 187-98.

[7] Yamanouchi, K., Soeta, C., Naito, K., \& Tojo, H. (2000). Expression of Myostatin Gene in Regenerating Skeletal Muscle of the Rat and Its Localization. Biochemical and Biophysical Research Communications, 270(2), 510-6.

[8] Musaro, A., Giacinti, C., Pelosi, L., Dobrowolny, G., Barberi, L., Nardis, C., et al. (2007). Stem cell-mediated muscle regeneration and repair in aging and neuromuscular diseases. European journal of histochemistry : EJH, 51(1), 35-43, Epub 2007/08/21.

[9] Hyatt, J. P., Roy, R. R., Baldwin, K. M., \& Edgerton, V. R. (2003). Nerve activity-independent regulation of skeletal muscle atrophy: role of MyoD and myogenin in satellite cells and myonuclei. American journal of physiology Cell physiology, 285(5), C1161-73, Epub 2003/07/04.

[10] Gayraud-Morel, B., Chretien, F., \& Tajbakhsh, S. (2009). Skeletal muscle as a paradigm for regenerative biology and medicine. Regenerative medicine, 4(2), 293-319, Epub 2009/03/26.

[11] Mitchell, K. J., Pannerec, A., Cadot, B., Parlakian, A., Besson, V., Gomes, E. R., et al. (2010). Identification and characterization of a non-satellite cell muscle resident progenitor during postnatal development. Nat Cell Biol, 12(3), 257-66, Epub 2010/02/02.

[12] Uezumi, A., Fukada, S-i., Yamamoto, N., Takeda, Si., \& Tsuchida, K. (2010). Mesenchymal progenitors distinct from satellite cells contribute to ectopic fat cell formation in skeletal muscle. Nat Cell Biol, 12(2), 143-52.

[13] Cooper, RN, Tajbakhsh, S., Mouly, V., Cossu, G., Buckingham, M., \& Butler-Browne, G. S. (1999). In vivo satellite cell activation via Myf5 and MyoD in regenerating mouse skeletal muscle. Journal of cell science, 112(Pt 17), 289-901, Epub 1999/08/13.

[14] White, J. P., Baltgalvis, K. A., Sato, S., Wilson, L. B., \& Carson, J. A. (2009). Effect of nandrolone decanoate administration on recovery from bupivacaine-induced muscle injury. Journal of Applied Physiology, 107(5), 1420-30.

[15] Politi, P. K., Havaki, S., Manta, P., \& Lyritis, G. (2006). Bupivacaine-induced regeneration of rat soleus muscle: ultrastructural and immunohistochemical aspects. Ultrastructural Pathology, 30(6), 461-9.

[16] Jones, GH. (1982). Protein synthesis in bupivacaine (Marcaine)-treated, regenerating skeletal muscle. Muscle \& nerve, 5(4), 281-90.

[17] Rosenblatt, J., \& Woods, R. (1992). Hypertrophy of rat extensor digitorum longus muscle injected with bupivacaine. A sequential histochemical, immunohistochemical, histological and morphometric study. Journal of Anatomy, 181(Pt 1), 11.

[18] Nonaka, I., Takagi, A., Ishiura, S., Nakase, H., \& Sugita, H. (1983). Pathophysiology of muscle fiber necrosis induced by bupivacaine hydrochloride (Marcaine). Acta Neuropathologica, 60(3), 167-74. 
[19] Irwin, W., Fontaine, E., Agnolucci, L., Penzo, D., Betto, R., Bortolotto, S., et al. (2002). Bupivacaine Myotoxicity Is Mediated by Mitochondria. Journal of Biological Chemistry, 277(14), 12221-7.

[20] Steer, J. H., Mastaglia, F. L., Papadimitriou, J. M., \& Van Bruggen, I. (1986). Bupivacaine-induced muscle injury: The role of extracellular calcium. Journal of the Neurological Sciences, 73(2), 205-17.

[21] Ishiura, S., Nonaka, I., \& Sugita, H. (1986). Biochemical aspects of bupivacaine-induced acute muscle degradation. Journal of cell science, 83, 197-212, Epub 1986/07/01.

[22] Saito, Y., \& Nonaka, I. (1994). Initiation of satellite cell replication in bupivacaine-induced myonecrosis. Acta Neuropathologica, 88(3), 252-7.

[23] Chang, C., Chuang, S. T., Lee, C., \& Wei, J. (1972). Role of cardiotoxin and phospholipase $\mathrm{A}$ in the blockade of nerve conduction and depolarization of skeletal muscle induced by cobra venom. British journal of pharmacology, 44(4), 752.

[24] Czerwinska, A. M., Streminska, W., Ciemerych, M. A, \& Grabowska, I. (2012). Mouse gastrocnemius muscle regeneration after mechanical or cardiotoxin injury. Folia histochemica et cytobiological Polish Academy of Sciences, Polish Histochemical and Cytochemical Society, 50(1), 144-53, Epub 2012/04/26.

[25] Gutiérrez, J. Ma, \& Ownby, C. L. (2003). Skeletal muscle degeneration induced by venom phospholipases A2: insights into the mechanisms of local and systemic myotoxicity. Toxicon, 42(8), 915-31.

[26] Lin Shiau, S. Y., Huang, M. C., \& Lee, C. Y. (1976). Mechanism of action of cobra cardiotoxin in the skeletal muscle. The Journal of pharmacology and experimental therapeutics, 196(3), 758-70, Epub 1976/03/01.

[27] Fletcher, J. E., \& Lizzo, F. H. (1987). Contracture induction by snake venom cardiotoxin in skeletal muscle from humans and rats. Toxicon, 25(9), 1003-10, Epub 1987/01/01.

[28] Fletcher, J. E., Jiang, S. M., Gong-H, Q., Yudkowsky, M. L., \& Wieland, S. J. (1991). Effects of a cardiotoxin from Naja naja kaouthia venom on skeletal muscle: Involvement of calcium-induced calcium release, sodium ion currents and phospholipases A2 and C. Toxicon, 29(12), 1489-500.

[29] Ownby, C. L., Fletcher, J. E., \& Colberg, T. R. (1993). Cardiotoxin 1 from cobra (Naja naja atra) venom causes necrosis of skeletal muscle in vivo. Toxicon, 31(6), 697-709.

[30] Fourie, A. M., Meltzer, S., Berman, M. C., \& Louw, A. I. (1983). The effect of cardiotoxin on $(\mathrm{Ca} 2++\mathrm{Mg} 2+)$-ATPase of the erythrocyte and sarcoplasmic reticulum. Biochemistry international, 6(5), 581-91, Epub 1983/05/01.

[31] Jagodzinski, N. A., Weerasinghe, C., \& Porter, K. (2010). Crush injuries and crush syndrome- a review. Part 2: the local injury. Trauma, 12(3), 133-48. 
[32] Bassaglia, Y., \& Gautron, J. (1995). Fast and slow rat muscles degenerate and regenerate differently after whole crush injury. Journal of muscle research and cell motility, 16(4), 420-9.

[33] Järvinen, T. A. H., Järvinen, T. L. N., Kääriäinen, M., Kalimo, H., \& Järvinen, M. (2005). Muscle Injuries. The American Journal of Sports Medicine, 33(5), 745-64.

[34] Winkler, T., von Roth, P., Matziolis, G., Schumann, M. R., Hahn, S., Strube, P., et al. (2011). Time course of skeletal muscle regeneration after severe trauma. Acta orthopaedica, 82(1), 102-11, Epub 2010/12/15.

[35] Ghaly, A., \& Marsh, D. R. (2010). Ischaemia-reperfusion modulates inflammation and fibrosis of skeletal muscle after contusion injury. International journal of experimental pathology, 91(3), 244-55, Epub 2010/04/01.

[36] Iwata, A., Fuchioka, S., Hiraoka, K., Masuhara, M., \& Kami, K. (2010). Characteristics of locomotion, muscle strength, and muscle tissue in regenerating rat skeletal muscles. Muscle E nerve, 41(5), 694-701, Epub 2010/04/21.

[37] Zhang, L. Y., Ding, J. T., Wang, Y., Zhang, W. G., Deng, X. J., \& Chen, J. H. (2011). MRI quantitative study and pathologic analysis of crush injury in rabbit hind limb muscles. The Journal of surgical researche, 357-63, Epub 2010/11/03.

[38] Pereira, T., Gärtner, A., Amorim, I., Ribeiro, J., França, M., Armada-da-Silva, P., et al. Development of a skeletal muscle injury model in the rat and in vivo evaluation of the use of Human Mesenchymal Stem Cells (HMSCs) from the umbilical cord matrix in myectomy injury treatment. 17th annual Congress of the European College of Sport Science, Bruges- Belgium.

[39] Merritt, E. K., Hammers, D. W., Tierney, M., Suggs, L. J., Walters, T. J., \& Farrar, R. P. (2010). Functional assessment of skeletal muscle regeneration utilizing homologous extracellular matrix as scaffolding. Tissue Engineering Part A, 16(4), 1395-405.

[40] Page, R. L., Malcuit, C., Vilner, L., Vojtic, I., Shaw, S., Hedblom, E., et al. (2011). Restoration of Skeletal Muscle Defects with Adult Human Cells Delivered on Fibrin Microthreads. Tissue Engineering Part A, 17(21-22), 2629-2640.

[41] Coppi, P. D., Bellini, S., Conconi, M. T., Sabatti, M., Simonato, E., Gamba, P. G., et al. (2006). Myoblast-acellular skeletal muscle matrix constructs guarantee a long-term repair of experimental full-thickness abdominal wall defects. Tissue engineering, 12(7), 1929-36.

[42] Sato, K., Li, Y., Foster, W., Fukushima, K., Badlani, N., Adachi, N., et al. (2003). Improvement of muscle healing through enhancement of muscle regeneration and prevention of fibrosis. Muscle E nerve, 28(3), 365-72, Epub 2003/08/21.

[43] Menetrey, J., Kasemkijwattana, C., Day, C., Bosch, P., Vogt, M., Fu, F., et al. (2000). Growth factors improve muscle healing in vivo. Journal of Bone and Joint Surgery-British, 82(1), 131-7. 
[44] Li, Y., \& Huard, J. (2002). Differentiation of Muscle-Derived Cells into Myofibroblasts in Injured Skeletal Muscle. The American journal of pathology, 161(3), 895-907.

[45] Valero, M. C., Huntsman, H. D., Liu, J., Zou, K., \& Boppart, MD. (2012). Eccentric exercise facilitates mesenchymal stem cell appearance in skeletal muscle. PloS one, 7(1), e29760, Epub 2012/01/19.

[46] Boppart, MD, Volker, S. E., Alexander, N., Burkin, D. J., \& Kaufman, S. J. (2008). Exercise promotes $\alpha 7$ integrin gene transcription and protection of skeletal muscle. American Journal of Physiology-Regulatory, Integrative and Comparative Physiology, 295(5), R1623.

[47] Dedkov, E. I., Kostrominova, T. Y., Borisov, A. B., \& Carlson, B. M. (2001). Reparative myogenesis in long-term denervated skeletal muscles of adult rats results in a reduction of the satellite cell population. Anat Rec, 263(2), 139-54, Epub 2001/05/22.

[48] Bruusgaard, J. C., \& Gundersen, K. (2008). In vivo time-lapse microscopy reveals no loss of murine myonuclei during weeks of muscle atrophy. The Journal of clinical investigation, 118(4), 1450-7, Epub 2008/03/05.

[49] IJ-P, J., Meek, M. F., \& Gramsbergen, A. (2005). Long-term reinnervation effects after sciatic nerve lesions in adult rats. Annals of anatomy = Anatomischer Anzeiger : official organ of the Anatomische Gesellschaft, 187(2), 113-20, Epub 2005/05/20.

[50] Edgerton, V. R., \& Roy, R. R. (2002). How selective is the reinnervation of skeletal muscle fibers? Muscle \& nerve, 25(6), 765-7, 2002/07/13.

[51] Ijkema-Paassen, J., Meek, M. F., \& Gramsbergen, A. (2001). Muscle differentiation after sciatic nerve transection and reinnervation in adult rats. Annals of anatomy = Anatomischer Anzeiger : official organ of the Anatomische Gesellschaft, 183(4), 369-77, 2001/08/18.

[52] Cebasek, V., Radochova, B., Ribaric, S., Kubinova, L., \& Erzen, I. (2006). Nerve injury affects the capillary supply in rat slow and fast muscles differently. Cell Tissue Res, 323(2), 305-12, 2005/09/15.

[53] Mc Geachie, J., \& Grounds, M. (1989). The onset of myogenesis in denervated mouse skeletal muscle regenerating after injury. Neuroscience, 28(2), 509-14.

[54] Gramsbergen, A., van Eykern, L. A., \& Meek, M. F. (2001). Sciatic nerve transection in adult and young rats: abnormal EMG patterns during locomotion. Equine veterinary journal, 33(S33), 36-40.

[55] Siu, P. M., \& Always, S. E. (2005). Mitochondria-associated apoptotic signalling in denervated rat skeletal muscle. The Journal of physiology, 565(Pt 1), 309-23, 2005/03/19.

[56] Bulken-Hoover, JD, Jackson, W. M., Ji, Y., Volger, J. A., Tuan, R. S., \& Nesti, L. J. (2011). Inducible Expression of Neurotrophic Factors by Mesenchymal Progenitor Cells Derived from Traumatically Injured Human Muscle. Molecular biotechnology, 2011/09/10. 
[57] Gärtner, A., Pereira, T., Simões, M. J., Armada-da-Silva, P., França, M. L., Sousa, R., et al. (2012). Use of hybrid chitosan membranes and MSC cells for promoting nerve regeneration in an axonotmesis rat model. Neural Regeneration Research, (in press).

[58] Gärtner, A., Pereira, T., Amorim, I., Ribeiro, J., \& França, M. L. P. A-d-S. (2012). Use of poly(DL-lactide- $\varepsilon$-caprolactone) PLC membranes and MSC cells for promoting nerve regeneration in an axonotmesis rat model: in vitro and in vivo analysis. Differentiation, (submitted).

[59] Maurício, A. C., Gärtner, A., Armada-da-Silva, P., Amado, S., Pereira, T., Veloso, A. P., et al. (2011). Cellular Systems and Biomaterials for Nerve Regeneration in Neurotmesis Injuries. Pignatello $R$, editor. Biomaterials Applications for Nanomedicine, 978-9-53307-661-4, Available from: InTech.

[60] Luis, A. L., Rodrigues, J. M., Geuna, S., Amado, S., Shirosaki, Y., Lee, J. M., et al. (2008). Use of PLGA 90:10 scaffolds enriched with in vitro-differentiated neural cells for repairing rat sciatic nerve defects. Tissue Eng Part A, 14(6), 979-93, 2008/05/02.

[61] Luis, A. L., Rodrigues, J. M., Geuna, S., Amado, S., Simoes, M. J., Fregnan, F., et al. (2008). Neural cell transplantation effects on sciatic nerve regeneration after a standardized crush injury in the rat. Microsurgery, 28(6), 458-70, 2008/07/16.

[62] Amado, S., Rodrigues, J. M., Luis, A. L., Armada-da-Silva, P. A., Vieira, M., Gartner, A., et al. (2010). Effects of collagen membranes enriched with in vitro-differentiated N1E-115 cells on rat sciatic nerve regeneration after end-to-end repair. J Neuroeng Rehabil, 7, 7, 2010/02/13.

[63] Simoes, M. J., Amado, S., Gartner, A., Armada-Da-Silva, P. A., Raimondo, S., Vieira, M., et al. (2010). Use of chitosan scaffolds for repairing rat sciatic nerve defects. Ital J Anat Embryol, 115(3), 190-210, 2011/02/04.

[64] Maurício, A. C. Cellular Systems and Biomaterials for Nerve Regeneration in Neurotmesis Injuries.

[65] Brandl, F., Sommer, F., \& Goepferich, A. (2007). Rational design of hydrogels for tissue engineering: impact of physical factors on cell behavior. Biomaterials, 28(2), 134-46, 2006/10/03.

[66] Fedorovich, N. E., Alblas, J., de Wijn, J. R., Hennink, W. E., Verbout, A. J., \& Dhert, W. J. A. (2007). Hydrogels as Extracellular Matrices for Skeletal Tissue Engineering: State-of-the-Art and Novel Application in Organ Printing. Tissue engineering, 13(8), 1905-25.

[67] Coelho, J., Ferreira, P., Alves, P., Cordeiro, R., Fonseca, A., Góis, J., et al. (2010). Drug delivery systems: Advanced technologies potentially applicable in personalized treatments. The EPMA Journal, 1(1), 164-209.

[68] Rehfeldt, F., Engler, A. J., Eckhardt, A., Ahmed, F., \& Discher, D. E. (2007). Cell responses to the mechanochemical microenvironment--implications for regenerative medicine and drug delivery. Adv Drug Deliv Rev ‘2007/09/29 , 59(13), 1329-39. 
[69] Lee, M., Wu, B. M., \& Dunn, J. C. (2008). Effect of scaffold architecture and pore size on smooth muscle cell growth. Journal of biomedical materials research Part A, 87(4), 1010-6, 2008/02/08.

[70] Seliktar, D. (2012). Designing cell-compatible hydrogels for biomedical applications. Science, 336(6085), 1124-8, 2012/06/02.

[71] Garg, T., Singh, O., Arora, S., \& Murthy, R. (2012). Scaffold: a novel carrier for cell and drug delivery. Critical reviews in therapeutic drug carrier systems, 29(1), 1-63, 2012/02/24.

[72] Rihova, B. (2000). Immunocompatibility and biocompatibility of cell delivery systems. Adv Drug Deliv Rev, 42(1-2), 65-80, 2000/08/16.

[73] Lyons, F., Partap, S., \& O’Brien, F. J. (2008). Part 1: scaffolds and surfaces. Technology and health care : official journal of the European Society for Engineering and Medicine, 16(4), 305-17, 2008/09/09.

[74] Martino, M. M., Mochizuki, M., Rothenfluh, D. A., Rempel, S. A., Hubbell, J. A., \& Barker, T. H. (2009). Controlling integrin specificity and stem cell differentiation in 2D and 3D environments through regulation of fibronectin domain stability. Biomaterials, 30(6), 1089-97, 08/11/26.

[75] Schmidt, J. J., Rowley, J., \& Kong, H. J. (2008). Hydrogels used for cell-based drug delivery. Journal of Biomedical Materials Research Part A, 87(4), 1113-22.

[76] Freyman, T. M., Yannas, I. V., \& Gibson, L. J. (2001). Cellular materials as porous scaffolds for tissue engineering. Progress in Materials Science, 46(3-4), 273-82.

[77] Tejas, Shyam. K., \& Mauli, A. (2008). Functions and Requirements of Synthetic Scaffolds in Tissue Engineering. Nanotechnology and Tissue Engineering: CRC Press, 53-86.

[78] Hoffman, A. S. (2002). Hydrogels for biomedical applications. Advanced drug delivery reviews, 54(1), 3-12.

[79] Tan, H., \& Marra, K. G. (2010). Injectable, Biodegradable Hydrogels for Tissue Engineering Applications. Materials, 3(3), 1746-67.

[80] Yu, L., \& Ding, J. (2008). Injectable hydrogels as unique biomedical materials. Chemical Society reviews, 37(8), 1473-81.

[81] Nguyen, M. K., \& Lee, D. S. (2010). Injectable Biodegradable Hydrogels. Macromolecular Bioscience, 10(6), 563-79.

[82] Goessl, A., Tirelli, N., \& Hubbell, J. A. (2004). A hydrogel system for stimulus-responsive, oxygen-sensitive in situ gelation. Journal of biomaterials science, Polymer edition, 15(7), 895-904, 2004/08/21.

[83] Nguyen, K. T., \& West, J. L. (2002). Photopolymerizable hydrogels for tissue engineering applications. Biomaterials, 23(22), 4307-14. 
[84] Shim, W. S., Yoo, J. S., Bae, Y. H., \& Lee, D. S. (2005). Novel injectable pH and temperature sensitive block copolymer hydrogel. Biomacromolecules, 6(6), 2930-4, 2005/11/15

[85] Borschel, G. H., Dennis, R. G., \& Kuzon, W. M. Jr. (2004). Contractile skeletal muscle tissue-engineered on an acellular scaffold. Plastic and reconstructive surgery, 113(2), 595-602, discussion 3-4, 2004/02/06.

[86] Ahmed, T. A. E., Dare, E. V., \& Hincke, M. (2008). Fibrin: a versatile scaffold for tissue engineering applications. Tissue Engineering Part B: Reviews, 14(2), 199-215.

[87] Huang, Y. C., Dennis, R. G., Larkin, L., \& Baar, K. (2005). Rapid formation of functional muscle in vitro using fibrin gels. J Appl Physiol, 98(2), 706-13, 2004/10/12.

[88] Koning, M., Harmsen, M. C., van Luyn, M. J. A., \& Werker, P. M. N. (2009). Current opportunities and challenges in skeletal muscle tissue engineering. Journal of tissue engineering and regenerative medicine, 3(6), 407-15.

[89] Lee, K. Y., \& Mooney, D. J. (2012). Alginate: properties and biomedical applications. Progress in polymer science, 37(1), 106-26, 2011/11/30.

[90] Pawar, S. N., \& Edgar, K. J. (2012). Alginate derivatization: a review of chemistry, properties and applications. Biomaterials, 33(11), 3279-305, 2012/01/28.

[91] Zorlutuna, P., Jeong, J. H., Kong, H., \& Bashir, R. (2011). Stereolithography-Based Hydrogel Microenvironments to Examine Cellular Interactions. Adv Funct Mater, 21(19), 3642-51.

[92] Lei, Y., Gojgini, S., Lam, J., \& Segura, T. (2011). The spreading, migration and proliferation of mouse mesenchymal stem cells cultured inside hyaluronic acid hydrogels. Biomaterials, 32(1), 39-47, 2010/10/12.

[93] Prestwich, G. D. (2011). Hyaluronic acid-based clinical biomaterials derived for cell and molecule delivery in regenerative medicine. Journal of controlled release : official journal of the Controlled Release Society, 155(2), 193-9, 2011/04/26.

[94] Gauvin, R., Parenteau-Bareil, R., Dokmeci, M. R., Merryman, W. D., \& Khademhosseini, A. (2012). Hydrogels and microtechnologies for engineering the cellular microenvironment. Wiley interdisciplinary reviews Nanomedicine and nanobiotechnology, 4(3), 235-46, 2011/12/07.

[95] Fossett, E., \& Khan, W. S. (2012). Optimising human mesenchymal stem cell numbers for clinical application: a literature review. Stem cells international, 2012, 465259, 2012/03/27.

[96] Le Blanc, K., \& Ringden, O. (2005). Immunobiology of human mesenchymal stem cells and future use in hematopoietic stem cell transplantation. Biol Blood Marrow Transplant, 11(5), 321-34, 2005/04/23.

[97] Wakitani, S., Imoto, K., Yamamoto, T., Saito, M., Murata, N., \& Yoneda, M. (2002). Human autologous culture expanded bone marrow mesenchymal cell transplanta- 
tion for repair of cartilage defects in osteoarthritic knees. Osteoarthritis and cartilage OARS, Osteoarthritis Research Society, 10(3), 199-206, 2002/03/01.

[98] Wang, L., Ott, L., Seshareddy, K., Weiss, M. L., \& Detamore, MS. (2011). Musculoskeletal tissue engineering with human umbilical cord mesenchymal stromal cells. Regen Med, 6(1), 95-109, 2010/12/24.

[99] Friedenstein, A. J., Petrakova, K. V., Kurolesova, A. I., \& Frolova, G. P. (1968). Heterotopic of bone marrow. Analysis of precursor cells for osteogenic and hematopoietic tissues. Transplantation, 6(2), 230-47, 1968/03/01.

[100] Togel, F., Weiss, K., Yang, Y., Hu, Z., Zhang, P., \& Westenfelder, C. (2007). Vasculotropic, paracrine actions of infused mesenchymal stem cells are important to the recovery from acute kidney injury. American journal of physiology, Renal physiology, 292(5), F1626-35, 2007/01/11.

[101] Zhang, M., Mal, N., Kiedrowski, M., Chacko, M., Askari, A. T., Popovic, Z. B., et al. (2007). SDF-1 expression by mesenchymal stem cells results in trophic support of cardiac myocytes after myocardial infarction. FASEB journal : official publication of the Federation of American Societies for Experimental Biology, 21(12), 3197-207, 2007/05/15.

[102] Mezey, E., \& Chandross, K. J. (2000). Bone marrow: a possible alternative source of cells in the adult nervous system. European journal of pharmacology, 405(1-3), 297-302, 2000/10/18

[103] Brazelton, T. R., Rossi, F. M., Keshet, G. I., \& Blau, H. M. (2000). From marrow to brain: expression of neuronal phenotypes in adult mice. Science, 290(5497), 1775-9, 2000/12/02.

[104] Bongso, A., Fong-Y, C., \& Gauthaman, K. (2008). Taking stem cells to the clinic: Major challenges. Journal of Cellular Biochemistry, 105(6), 1352-60.

[105] Conconi, M. T., Burra, P., Di Liddo, R., Calore, C., Turetta, M., Bellini, S., et al. (2006). CD105(+) cells from Wharton's jelly show in vitro and in vivo myogenic differentiative potential. Int J Mol Med, 18(6), 1089-96, 2006/11/08.

[106] Kadivar, M., Khatami, S., Mortazavi, Y., Shokrgozar, MA, Taghikhani, M., \& Soleimani, M. (2006). In vitro cardiomyogenic potential of human umbilical vein-derived mesenchymal stem cells. Biochemical and Biophysical Research Communications, 340(2), 639-47.

[107] Rantanen, J., Hurme, T., Lukka, R., Heino, J., \& Kalimo, H. (1995). Satellite cell proliferation and the expression of myogenin and desmin in regenerating skeletal muscle: evidence for two different populations of satellite cells. Laboratory investigation; a journal of technical methods and pathology, 72(3), 341-7, 1995/03/01. 
